\title{
Roland Barthes oder das Spiel mit den Bruchstücken der Liebe
}

Der originellste, prägnanteste und aus meiner Sicht für die Perspektivik unserer Vorlesung höchst relevante Versuch französischer Theoretiker, des Themas „Liebe“ habhaft zu werden, ist ein wissenschaftlicher Bestseller, der auch im deutschsprachigen Raum großen Erfolg verzeichnen konnte. Vielleicht ist er der einen oder dem anderen von Ihnen bereits bekannt und Sie haben den Band zuhause. Es handelt sich um die Fragments d'un discours amoureux des französischen Zeichentheoretikers und Philosophen Roland Barthes. Es ist ein Buch aus seinen letzten Lebensjahren, in denen Barthes sich aus dem Orbit der Gruppe Tel Quel verabschiedet hatte und seinen sehr eigenen Weg zu einer Art Zwitterwesen zwischen Denker und Schriftsteller ging. Ich möchte Ihnen diesen wichtigen Kopf des 20. Jahrhunderts vorstellen, damit Sie einen Einblick in seine intellektuelle Entwicklung erhalten können. Dabei nehme ich mir etwas Zeit und Raum, denn die Entwicklungen von Roland Barthes sind in vielerlei Hinsicht wegweisend für die Entwicklungen der Literatur- und Kulturtheorie der zweiten Hälfte des 20. Jahrhunderts und gerade auch für die Themenstellung „Liebe / Lesen“ von größter Bedeutung.

Roland Barthes wurde am 12. November 1915 im französischen Cherbourg geboren. Nach dem frühen Tod seines Vaters 1916, im Ersten Weltkrieg, zog er mit seiner Mutter Henriette zu den Großeltern nach Bayonne in den Südwesten Frankreichs, dem er zeitlebens emotional sehr verbunden blieb. Dort wuchs der Junge unter der Obhut dreier Frauen - der Großmutter, einer Tante sowie der geliebten Mutter (die als Buchbinderin arbeiten musste) - wohlbehütet, wenn auch vaterlos auf. Im Jahre 1924 zog er zusammen mit seiner Mutter Henriette nach Paris um, wo der schulisch hochbegabte Junge zunächst das Lycée Montaigne und später das renommierte Gymnasium Louis le Grand besuchte. Mit seiner Mutter und einem Stiefbruder lebte er bis Ende der fünfziger Jahre stets in finanziell recht prekären Situationen.

Früh begeisterte sich der junge Barthes für Literatur, Theater und Musik. Bald folgten den umfangreichen Lektüren erste literarische Versuche, die bereits einen Einblick in seine spätere Entwicklung gewähren. Nach dem Abitur 1933 wurde die angestrebte Aufnahme in die Elite-Hochschule Ecole Normale Supérieure durch eine Tuberkulose-Erkrankung im Mai 1934 unmöglich. Zwischen 1934 und 1946 verbrachte er insgesamt fast acht Jahre in Sanatorien zuerst in den Pyrenäen, später in den französischen und Schweizer Alpen. Zwar konnte er zwischen 1935 und 1939 an der Sorbonne das Studium der klassischen Literatur aufnehmen, doch schien nun die ursprünglich angestrebte brillante ENS-Karriere für immer 
unerreichbar zu sein. 1937 begann er einen kurzen Studienaufenthalt in Ungarn; und 1938 reiste er nach Athen und in die Inselwelt Griechenlands, zusammen mit den Mitgliedern der „Gruppe Antikes Theater“, die er an der Sorbonne mitbegründet hatte. Sein kurzer, Jahre später im Sanatorium veröffentlichter Text En Grèce wird für sein Schreiben und insbesondere seine Kurzschreibweise charakteristisch sein.

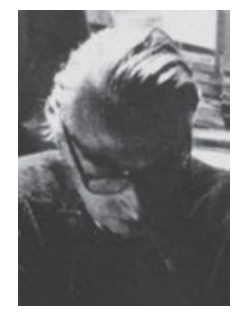

Abb. 19: Roland Barthes (Cherbourg, 1915 - Paris, 1980), am Schreibtisch in Paris, 1972.

Es folgten von 1939 bis 1940 eine Tätigkeit als Aushilfslehrer in Biarritz, von 1940 bis 1941 eine pädagogische Aushilfstätigkeit an Pariser Gymnasien, vor allem aber die Gesangsstunden bei dem berühmten Charles Panzéra, die er Ende 1941 wegen einer erneuten Tuberkulose-Erkrankung abbrechen musste und erst 1956 für eine kurze Zeit wieder aufnehmen konnte. 1943 schloss er während einer kurzfristigen Besserung seine Licence an der Sorbonne ab. Während seiner langen Jahre im Sanatorium unternahm Roland Barthes umfangreiche Lektüren, hielt Vorträge über Musik wie Literatur und verfasste erste literaturkritische Veröffentlichungen.

Nach dem Krieg kehrte er 1946 nach Paris zurück. Erneut lebte er mit seiner Mutter in einer schwierigen finanziellen Situation; Barthes' berufliche Lage war völlig ungeklärt. So nahm er 1947 eine Stelle als Bibliothekar und Lehrer am Institut Français in Bukarest an. Nach dessen Schließung aus politischen Gründen kam er Ende 1949 als Lektor im ägyptischen Alexandria unter. 1950 kehrte Barthes nach Paris zurück und übernahm bis 1952 eine Tätigkeit in der Kulturabteilung des französischen Außenministeriums. Barthes nahm literaturkritische und wissenschaftliche Gelegenheitsarbeiten an und erhielt von 1952 bis 1954 ein Arbeitsstipendium des Centre National de la Recherche Scientifique. Dort war er von 1955 bis 1959 im Bereich der Soziologie forschend tätig. Eine berufliche Sicherheit ergab sich jedoch erst in den sechziger Jahren, als Barthes von 1960 bis 1962 Directeur d'Etudes an der Ecole Pratique des Hautes Etudes im Bereich Sozial- und Wirtschaftswissenschaften, 1962 dann Directeur d'Etudes im Bereich Soziologie der Zeichen, Symbole und Darstellungen wurde. Diese Funktion übte er achtzehn Jahre lang aus.

In den sechziger Jahren wurde Roland Barthes zum Wortführer der Nouvelle Critique und $\mathrm{zu}$ einem der einflussreichsten Intellektuellen Frankreichs. Seine 
Seminare wurden legendär. Barthes unternahm Reisen nach Marokko, Japan und in die USA, die ihn in einen der innovativsten Reiseschriftsteller des 20. Jahrhunderts verwandelten. Die Ereignisse vom Mai 1968 blieben dem zur undogmatischen Linken gezählten Intellektuellen freilich fremd. 1969 trat er eine Gastdozentur in Rabat an, kehrte aber 1970 vorzeitig wieder nach Paris zurück, wo er seine (kleinen) Seminare in der für ihn charakteristischen gemeinschaftlichen Atmosphäre an der EPHE wieder aufnahm.

Neben Literatur und Musik widmete er sich nun zunehmend als Kritiker wie als Künstler der Malerei. 1974 reiste er mit Mitgliedern der Tel-Quel-Gruppe nach China, doch konnte er die Japan-Erfahrung nicht wiederholen: Sein Reisebericht ist gleichwohl bis heute höchst aufschlussreich, dokumentiert zugleich aber auch seine zunehmende Entfremdung von Tel Quel. 1976 wurde er auf Vorschlag von Michel Foucault auf den für ihn eigens eingerichteten Lehrstuhl für literarische Semiologie am renommierten Collège de France berufen. Roland Barthes war auf dem Höhepunkt seiner Karriere angelangt. Doch im Oktober 1977 starb seine Mutter: Die tiefe Trauer des Autors spiegelt sich eindrucksvoll in seinem Journal de deuil. Am 25. Februar 1980 wurde Barthes beim Überqueren einer Straße angefahren; er erholte sich von den Folgen des Unfalls nicht mehr und starb am 26. März 1980 in Paris.

1977 ist im Leben von Roland Barthes sicherlich ein entscheidendes Jahr. Denn in es fallen seine Antrittsvorlesung am Collège de France, der große Publikumserfolg seiner Fragments d'un discours amoureux, die Veranstaltung eines ihm gewidmeten Colloque de Cerisy sowie der erwähnte Tod seiner Mutter.

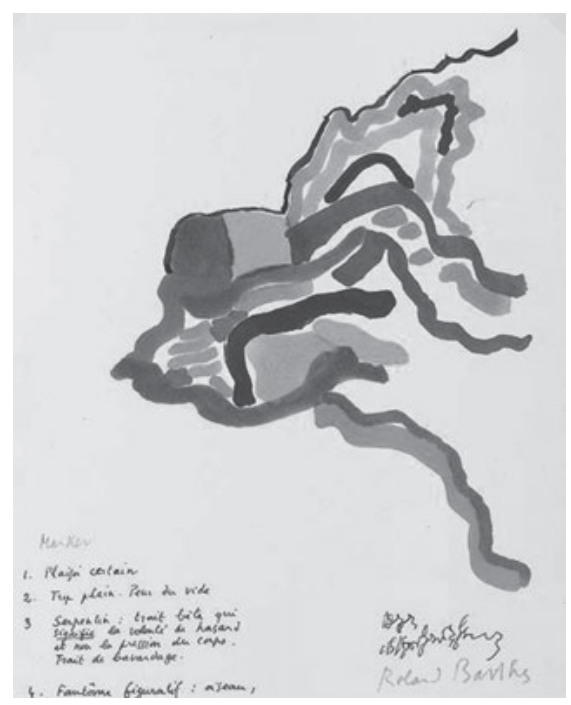

Abb. 20: „Plaisir certain“, Zeichnung von Roland Barthes, 1971. 


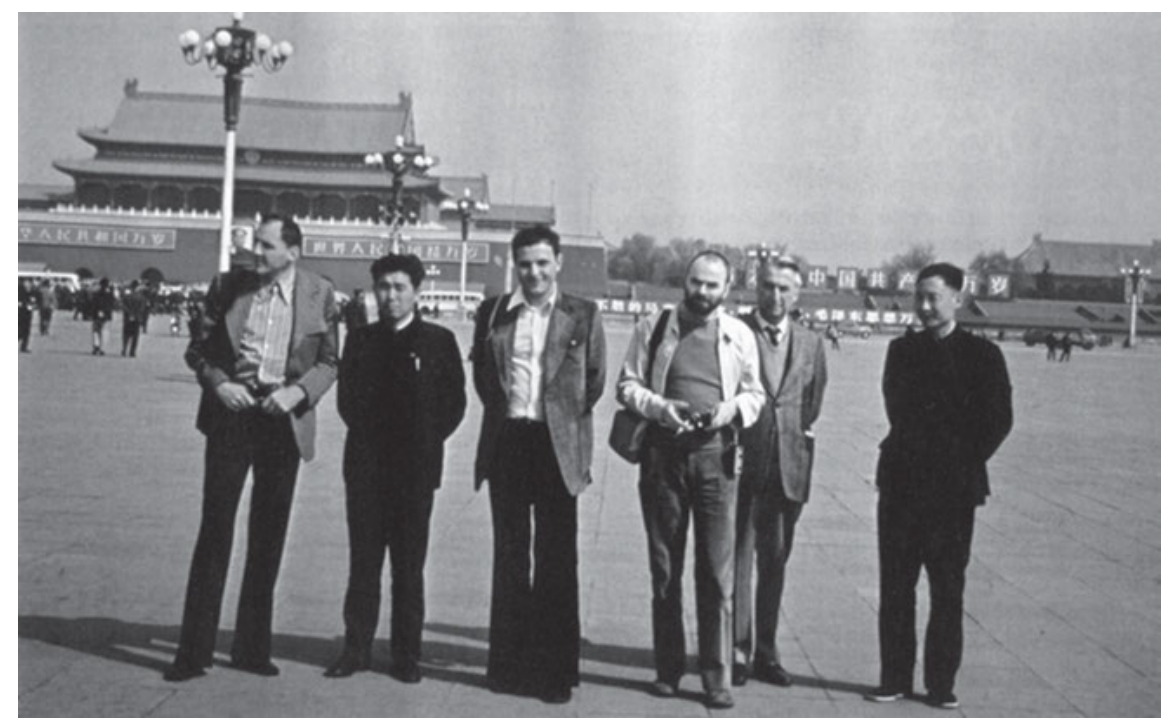

Abb. 21: Die von Julia Kristeva fotografierte Gruppe „Tel quel“ auf dem Tian’anmen-Platz, Peking, im April 1974.

Insofern sind seine Fragments noch ein glückliches Buch, wurde er nun doch einer breiten Öffentlichkeit als Schriftsteller und Denker bekannt, erhielt sogar einen Fernsehauftritt in Bernard Pivots berühmter Sendung Apostrophes - und noch war der Tod von Henriette Barthes, mit der er sein Leben geteilt hatte, nicht absehbar.

Die hybride Einheit von Barthes' erstmals zwischen 1993 und 1995 in einer Werkausgabe gesammelten Veröffentlichungen zeichnet in beispielloser Prägnanz den Weg eines französischen Intellektuellen von der produktiven Auseinandersetzung mit Jean-Paul Sartre und der Nouvelle Critique über Strukturalismus und Tel Quel bis hin zu poststrukturalistischen Positionen nach. Die Komplexität dieses Weges ist angesichts der ständigen Neubestimmungen der eigenen Position Barthes' beispiellos. Sein Lebensstil und seine publikumswirksame Selbstinszenierung gehören notwendig zu den schöpferischen Ausdrucksformen dieses sich gängigen Kategorisierungen stets entziehenden französischen Essayisten. Mit $L e$ Degré zéro de l'écriture (1953) katapultierte sich Barthes in die Theoriedebatten eines im Zeichen des Sartre'schen écrivain engagé stehenden Nachkriegsfrankreich. Existentialistisch geprägte Begriffe wie Engagement, Wahl und Solidarität werden von der inhaltlich-ideologischen auf die Ebene der écriture transponiert, die als der eigentliche Ort von Freiheit und Erlösung erscheint. Verfolgen wir hier den Weg von Roland Barthes noch kurz. 


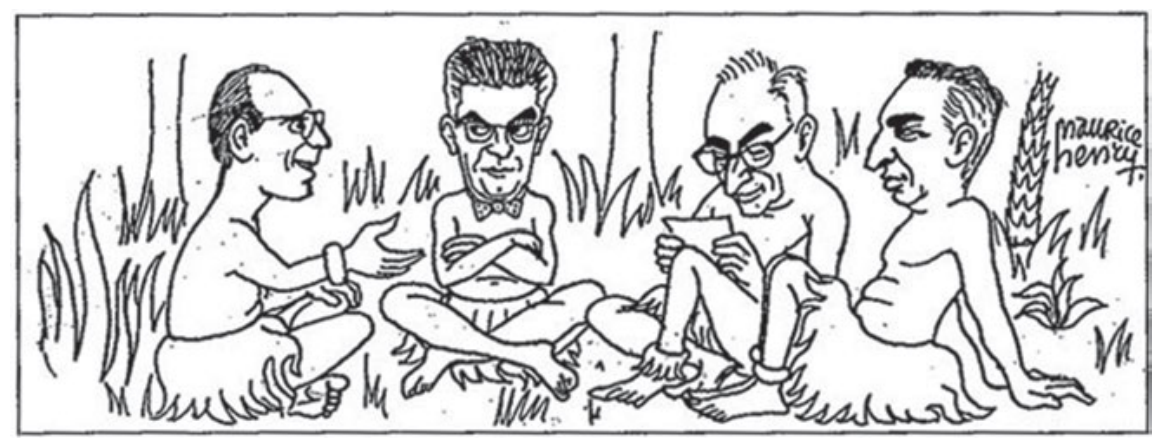

Abb. 22: Le déjeuner structuraliste : Michel Foucault, Jacques Lacan, Claude Lévi-Strauss et Roland Barthes.

Auch in seinem Michelet par lui-même (1954) ging es ihm vor allem um die Schreibweise des berühmten Historikers, dessen „Netz von Obsessionen“, so etwa sexuelle Repräsentationsmuster geschichtlicher Prozesse, er mit Hilfe existentialpsychoanalytischer Ansätze und mehr noch der critique thématique aufzudecken suchte. Die écriture courte seiner zunächst in Zeitschriften publizierten „Mythen des Alltags“ rundet er 1957 in seinem Band Mythologies mit dem Versuch ab, den Strukturalismus kulturkritisch auf die französische Gesellschaft und deren Mythen zu beziehen. Unvergessen seine Texte über Greta Garbo, über die neue $D S$ von Citroèn oder die Überschwemmungen in Paris. Spätestens mit diesem Band ist Roland Barthes in aller Munde und profiliert sich zunehmend als einer der führenden Intellektuellen Frankreichs. Strukturalistische Begriffspaare erfahren eine ideologiekritische und mehr noch kulturtheoretische Zuspitzung, wobei die oftmals verblüffenden Beobachtungen diesen Essayband auch außerhalb Frankreichs rasch zu einem Klassiker nicht nur der Zeichen- und Kulturtheorie werden lassen.

Doch Barthes wollte mehr. Mit der bewusst gegen die universitäre Kritik gerichteten Veröffentlichung von Sur Racine (1963) und seinen Essais critiques (1964), die sich als breit angelegte Untersuchung zum Moderne-Begriff lesen lassen, gelang Barthes die Festigung seiner geradezu ubiquitären Position als Vertreter der Nouvelle Critique im intellektuellen Feld Frankreichs, eine Position, die er mit seinem Machtwort in der von ihm ausgelösten Polemik, Critique et vérité (1966), untermauerte. Die am Ende von „Kritik und Wahrheit“ angestellten Überlegungen zeigen zugleich einen Barthes, der sich mit Autoren wie Gérard Genette, Algirdas Greimas, Umberto Eco oder Claude Bremond diskursanalytischen und narratologischen, aber mehr noch nietzscheanisch beziehungsweise dekonstuktivistisch eingefärbten Standpunkten der französischen Neoavantgarde und vor 
allem der frühen Tel Quel-Gruppe um Philippe Sollers, Jaques Derrida und Julia Kristeva nahe weiß.

Sind Elemente der Semiologie (1964) und Système de la mode (1967) noch dem Saussure'schen Paradigma, der strukturalen Anthropologie und einem weiten Kulturbegriff verpflichtet, so zeigt sich in seinem international vieldiskutierten Essay „La mort de l'auteur“ von 1967 eine philosophische Ausrichtung, in der Polyvalenz und Offenheit des Textes semiologisch und texttheoretisch radikalisiert werden und im Verschwinden des Autor-Subjekts, in der Rede vom „Tod des Autors“, sowie in der damit einhergehenden „Geburt des Lesers“ gipfeln. Lesen und Lektüre stehen jetzt im Fokus seiner literatur- und kulturtheoretischen Überlegungen.

Der Autor Barthes freilich arbeitet unermüdlich an seiner écriture courte, die ebenso seine 1969 entstandenen, aber erst postum veröffentlichten marokkanischen Reiseskizzen Incidents (1987) wie auch sein Japan-Buch L'empire des signes (1970) sowie $S / Z$ (1970) prägt. In der letztgenannten, auf den ersten Blick strukturalistisch anmutenden Mikroanalyse einer Novelle Balzacs sind die Gewichte vom Werk- zum (als Gewebe verschiedener Codes gedeuteten) Textbegriff und von der Produktion zur (textproduzierenden) Rezeption verschoben; Lektüre erscheint als Entfaltung einer unbeschränkten Sinn(en)vielfalt, eine Lesepraxis, die Barthes 1971 in Sade, Fourier, Loyola kanonverändernd vorführt. In einer Foucaults Begriff „Diskursbegründer“ recht verwandten Metaphorik werden die drei Titelfiguren als logothètes oder „Sprachbegründer“ gedeutet, wobei eine „Befreiung“ des Signifikanten vom Referentiellen grundlegend ist.

Aus einem übergreifenden Blickwinkel schöpft Roland Barthes nahezu das gesamte Spektrum an zentralen Stichworten der Theoriedebatten aus, wobei er selbst für zahlreiche theoretische Diskussionen Stichwortgeber ist. Zwischen Nietzsche und Lacan, Sade und Sollers siedelt sich Le Plaisir du texte (1973) an, das Barthes' letzte Schaffensperiode einleitet und diese in das Zeichen einer enthierarchisierten, jenseits binärer Oppositionen stehenden Erotik des Textes stellt. Die „Lust am Text“ öffnet sich am Ende zu einer erotischen Lust des Ohres an der Körperlichkeit der Stimme und zeichnet so Barthes' eigenwilligen Weg aus dem Textualitätsdogma von Tel Quel vor. Denn in Barthes' gesamtem Schaffen steht immer wieder die corporéité im Zentrum - und mit ihr Eros, Lust und Liebe.

Mit dem Körper kehrt eine imaginierte Subjektivität zurück, welche die Grundlage für die autobiographische Fiktion Roland Barthes par Roland Barthes (1975), für den Bestseller Fragments d'un discours amoureux (1977) - mit dem wir uns sogleich beschäftigen werden - wie zumindest teilweise für sein letztes Buch, La Chambre claire (1980) bildet. Nicht nur durch seine literar- und kulturtheoretischen Ansätze, sondern auch durch die ästhetische Gestaltung seiner Buchprojekte hat Barthes in seinem Spiel mit den Grenzen zwischen Metatext und 
(literarischem) Text die Schreibweise vieler, nicht nur französischer Autorinnen und Autoren bis in die Gegenwart geprägt. Was aber hatte der französische Autor zur Liebe zu sagen?

Kommen wir also zu jenen Fragments d'un discours amoureux, die neben seinen Mythologies zum größten Verkaufserfolg seiner wissenschaftlichschriftstellerischen Karriere wurden.

Mit den Fragments gelang Barthes, was im Regelfall nur Schriftstellerinnen und Schriftstellern vorbehalten bleibt: Er landete im Frühjahr 1977 einen wirklichen Bestseller. Nach einer rasch vergriffenen Startauflage von immerhin 15000 Exemplaren lässt sein Verlag noch im selben Jahr sieben weitere Auflagen drucken und verkauft 79000 Exemplare des Bandes allein im Jahre 1977. Der Erfolg übertrifft alle Erwartungen und überrascht auch den Autor selbst. Barthes konnte sich vor Interviewanfragen nicht nur bei Zeitungen und Zeitschriften, sondern auch in Rundfunk und Fernsehen kaum retten. Wiederum nur wenige Wochen später, im Juni 1977, findet das bereits erwähnte Kolloquium von Cerisy-la-Salle statt, das sich seinem bisherigen, teilweise aber auch bereits seinem künftigen Schaffen widmet. Ein Kolloquium in Cerisy stellte für französische Schriftsteller wie Philosophen die definitive Konsekration dar.

Barthes hatte eine Erklärung für den Erfolg seines Buches, die er in Cerisy äußerte. Er deutet diesen Erfolg so, dass sich „die Leute“ in seinem Buch über die Liebe „wiedererkennen würden, nicht etwa, weil es wahr wäre, sondern weil es geschrieben“ sei: „Weil ich an der Schreibweise dieses Buches gearbeitet habe, verkauft es sich, und nicht, weil es wahr ist." ${ }^{26}$ Also alles nur eine Frage von Form und Formulierung?

Diese Deutung durch Barthes selbst erklärt den Erfolg des Bandes ebenso wenig wie der durchaus witzige Einwurf des französischen Schriftstellers Alain Robbe-Grillet, bei den Fragmenten einer Sprache der Liebe handle es sich keineswegs um den ersten Roman von Barthes, sei der Autor des Michelet doch mittlerweile schon bei seinem fünften oder sechsten angelangt. Die Bemerkung des Hauptvertreters des nouveau roman warf freilich ein Schlaglicht auf das Schreiben von Barthes, dessen Sprache seit dem Erscheinen von Am Nullpunkt des Schreibens unablässig der Vorwurf gemacht wurde, preziös, unlesbar, unfranzösisch oder intellektualistisch zu sein. Roland Barthes hatte unter den beständigen Angriffen gegen seine Sprache, gegen seinen Stil, gegen seine écriture, stets sehr gelitten. Nun aber räumte er, zweifellos mit einem gewissen Wohlgefallen, ein, dass er immer häufiger gefragt werde, ob er gerade an einem Roman schreibe. In

26 Vgl. die Bemerkung Barthes' in Compagnon, Antoine (Hg.): Prétexte: Roland Barthes. Colloque de Cerisy. Paris: 10/18 1978, S. 219. 
einem Diskussionsbeitrag sprach er gar von einer ,journalistischen Offensive“, die aus ihm - koste es, was es wolle - einen Schriftsteller machen wolle, gemäß der Formel ,aber ja, Barthes ist ein Schriftsteller, das wissen wir schon seit langem “. ${ }^{27}$ Barthes bastelte offensichtlich an seinem eigenen Mythos.

Wie in seiner experimentellen Autobiographie Roland Barthes par Roland Barthes blieb Barthes auch in den Fragments d'un discours amoureux seiner Liebe zur écriture courte, zum Fragment, wieder einmal treu. Der gesamte Band wird von einer Formel eröffnet, welche für den gesamten Band die Stimme gleichsam programmiert: Denn es ist „ein Liebender, der hier spricht und sagt““. ${ }^{28}$ Es handelt sich folglich um einen discours amoureux, den Diskurs eines Liebenden, womit gleichzeitig ein Diskurs im transphrastischen und narratologischen Sinne und ein Sprechen, eine mündliche Rede gemeint ist, welche „ein Liebender“ auf den folgenden Seiten artikuliert. Beginnen wir ausgehend von dieser Bestimmung unseren Durchgang durch Barthes' Text, der wunderbar die Mehrdeutigkeit von Metatext und literarischem Spiel aufrecht erhält, so dass man zwischen Zitaten, Kommentaren und Setzungen sowie Aphorismen bald nicht mehr weiß, auf welcher Textebene man sich befindet.

So, wie der Autor (oder besser die Autorfigur) von Barthes zunächst aus dem Text vertrieben wurde, um dann - in Roland Barthes par Roland Barthes - als Autorfiktion wieder zurückkehren zu dürfen, kehrt nun auch das Subjekt wieder in den literarischen Text "heim“: als eine Fiktion oder, genauer noch, als eine Figuration. In Die Lust am Text hatte Barthes den Autor als eine von ihm benötigte „Figur“29 bezeichnet, deren Notwendigkeit spätestens in seiner experimentellen Autobiographie erkennbar wurde, da nur so ein Spiel wechselseitiger Spiegelungen zwischen „Subjekt(en)“ und „Objekt(en)“ des Schreibens geschaffen werden konnte. Es geht also keinesfalls um den realen Autor, um den Autor mit Haut und Haaren, Fleisch und Knochen. Ähnlich verwendet Barthes nun das Subjekt des Liebenden als eine Figur, in der sich die verschiedensten Fragmente eines Diskurses bündeln lassen. Oder besser als eine Figuration, die in unterschiedlichste Figuren trennbar und damit durchbuchstabierbar ist. Der Liebende wird daher nicht als Individuum mit einer psychologischen „Tiefe“ dargestellt, sondern in den Strukturierungen seines Sprechens inszeniert. Er wird in einzelne figurale Bewegungen unterteilt, die gesondert untersucht werden.

Diese Anlage seines Textes entstand nicht spontan, sondern entwickelte sich in ihm über einen längeren Zeitraum. Vorüberlegungen zu einem solchen Buch

27 Ebda., S. 414 sowie S. 251.

28 Barthes, Roland: Fragments d'un discours amoureux. Paris: Seuil 1977, S. 13.

29 Barthes, Roland: Fragments d'un discours amoureux. In (ders.): Oeuvres complètes Edition établie et présentée par Eric Marty. 3 Bde. Paris: Seuil 1993-1995, Bd. II, S. 1508. 
finden sich bereits in Kapitel LXXV von $S / Z$. Denn dort war Barthes ausgehend von Balzacs Novelle Sarrasine auf die Variationen von Liebesschwüren und Liebesverweigerungen eingegangen: „Nur eine historische Inventur der Formen der Liebessprache (parole amoureuse) könnte diese Variationen ausnutzen und uns den Sinn des „Parlez-moi d'amour“ aufzeigen, wenn dieser Sinn sich weiterentwickelt hat usw. Die Unendlichkeit kommt ihrerseits von der Wiederholung: die Wiederholung, das ist genau, dass es keinen Grund gibt aufzuhören."30 Was im Liebesdiskurs unbedingt vermieden werden sollte, das ist der Schlusspunkt.

In Barthes' $S / Z$ ist noch nicht von Diskurs, wohl aber von einem mündlichen Sprechen die Rede, das die Liebenden auszeichnet. Dieses Sprechen soll nun im realisierten Projekt der Fragments d'un discours amoureux in Szene gesetzt werden: Dafür braucht Barthes die Figur eines Subjekts. Zugleich muss das Sprechen aber auch auf ein historisches Inventar hin geöffnet werden, und dies wäre im Gegensatz zur individuellen Ebene der parole die intersubjektive, „kollektive“ Ebene des Diskurses. Der Begriff des Diskurses ist für Barthes hier essentiell und deshalb ist es leider auch grundfalsch, wie in der deutschen Übersetzung von den „Fragmenten einer Sprache der Liebe“ zu sprechen. Ich spreche daher lieber von den Fragmenten eines Diskurses der Liebe, was den Absichten Roland Barthes' wesentlich stärker entspricht.

Dem gesamten Band hat Roland Barthes - wie in den siebziger Jahren recht oft - eine Art Gebrauchsanweisung des Buches vorangestellt unter dem Titel „Comment est fait ce livre“. Damit ist in didaktischer Hinsicht eine Art Leseanweisung verbunden, die das Buch auch für breitere Leserschichten öffnet - ohne dass Barthes freilich an einen derartigen Publikumserfolg gedacht hätte. Dort heißt es gleich zu Beginn in wohlgesetzten Worten:

Die Beschreibung des Diskurses der Liebe ist also durch seine Nachbildung ersetzt worden, und dieser Diskurs hat seine entscheidende Hauptperson zurückerstattet bekommen, das Ich, und zwar so, dass eine Ausdrucksweise inszeniert wurde, keine Analyse. Was vorgestellt wird, ist, wenn man so will, ein Porträt, aber kein psychologisches, sondern ein strukturales: es gibt einen sprachlichen Ort zur Lektüre auf: den Ort jemandes, der für sich, als Liebender, spricht, der angesichts des anderen (des Liebesobjektes) spricht, der seinerseits schweigt. ${ }^{31}$

Ich muss mich an dieser Stelle für die recht holprige Übersetzung entschuldigen. Sie stammt ausnahmsweise nicht von mir, sondern ist dem Suhrkamp-Band entnommen, der ja schon den fehlerhaften Titel trägt; übersetzt wurde übrigens

30 Barthes, Roland: S/Z. In (ders.): Oeuvres complètes, Bd. II, S. 674.

31 Barthes, Roland: Fragmente einer Sprache der Liebe. Aus dem Französischen von Hans-Horst Henschen. Frankfurt a. M. : Suhrkamp 1984, S. 15. 
von Hans-Horst Henschen, einem mit Barthes bestens vertrauten Übersetzer und Interpreten.

Zentral ist folglich die Figur eines Sprechenden, eines „Ich“. Der Diskurs dieses (,eines“) Liebenden greift auf ein heterogenes, historisch wie individualgeschichtlich aufgehäuftes Material zurück, das keineswegs historisiert, sondern in der Figur des Sprechenden aktualisiert, vergegenwärtigt wird. Damit ist keine Psychologisierung dieser Figur verbunden. Wir treten vielmehr in ein Netz von Beziehungen, in eine Welt intertextueller Bezüge ein. In einer dem Buch nachgestellten „Tabula gratulatoria“ werden Bezugspunkte dieses Diskurses der Liebe oder dieses liebenden Diskurses genannt. Wie sieht dieses Beziehungsnetz aus?

In einer ersten Gruppe finden sich mit Barthes befreundete Schriftsteller (wie Sollers oder Sarduy), Mitstreiter oder Teilnehmer seiner Seminare an der Ecole Pratique des Hautes Etudes. Die zweite Gruppe wird von einem Einzelwerk ausgefüllt, Goethes Die Leiden des jungen Werther, dessen französische Übersetzung Roland Barthes zum zweifellos wichtigsten Intertext seines Buches machte. Dies ist bemerkenswert, gibt diese Wahl doch schon eine gewisse Stoßrichtung für den Liebesdiskurs vor. In einer dritten Gruppe dieser Ehrentafel finden sich verschiedenste Autoren von Balzac, Bataille und Baudelaire, über die bereits mehrfach erwähnten Nietzsche-Studien von Deleuze und Klossowski, die Schriften Freuds und Lacans, Diderots und Flauberts, von Novalis und Proust, bis hin zu Denis de Rougemont und Sartre, Stendhal und Szondi. In der vierten und letzten Gruppe schließlich treffen wir auf Komponisten wie Wagner, Mozart und Schubert; aber auch auf Buñuels Film Der diskrete Charme der Bourgeoisie wird verwiesen. Eine bunte Gemengelage an Liebesdiskursen, würde man auf den ersten Blick sagen. Und sie alle überschneiden sich im „Ich“.

Auf diese Weise wird ein breiter literarischer Raum abgesteckt, der Literatur und Musik, Freundeskreis und Film, Philosophie und Psychoanalyse umfasst; ihm werden in den Fragmenten eine Vielzahl von leicht erkennbaren Biographemen Barthes', von Dialogen mit Freunden und schließlich ein Ausschnitt aus dem Gemälde „Tobias und der Engel“ aus der Werkstatt von Andrea del Verrocchio beigegeben, das die vordere Umschlagseite des Bandes ziert. Durch den Einbau von Autobiographemen wird aus den Fragments unter der Hand auch und gerade ein zutiefst autobiographisches Buch, dem auch die durchaus subjektiven Lektüren und Lesarten der einbezogenen Texte entsprechen. Übrigens hat Barthes nicht umsonst den Verweis auf sein eigenes Leben unter dem Stichpunkt „Références“ hinzugefügt: „Il y a enfin ce qui vient de ma propre vie.“32 Hier wird nicht allein die autobiographische, sondern weitaus mehr die lebenswissenschaftliche

32 Barthes, Roland: Fragments d'un discours amoureux, S. 12. 
Dimension deutlich einbezogen, auch wenn diese als Begriff selbstverständlich nicht gegeben ist. Denn die Fragments bilden ein Buch, das mit Hilfe literarischer Bezugsquellen wie auch unter Rückgriff auf das Leben des Autors ein Wissen vom Leben im Leben und auch ein Wissen vom Zusammenleben und vom Überleben aus der Perspektivik eines Erlebenswissens darstellt. Dies ist, wie man vorsichtig anführen darf, ein Gutteil Forschung.

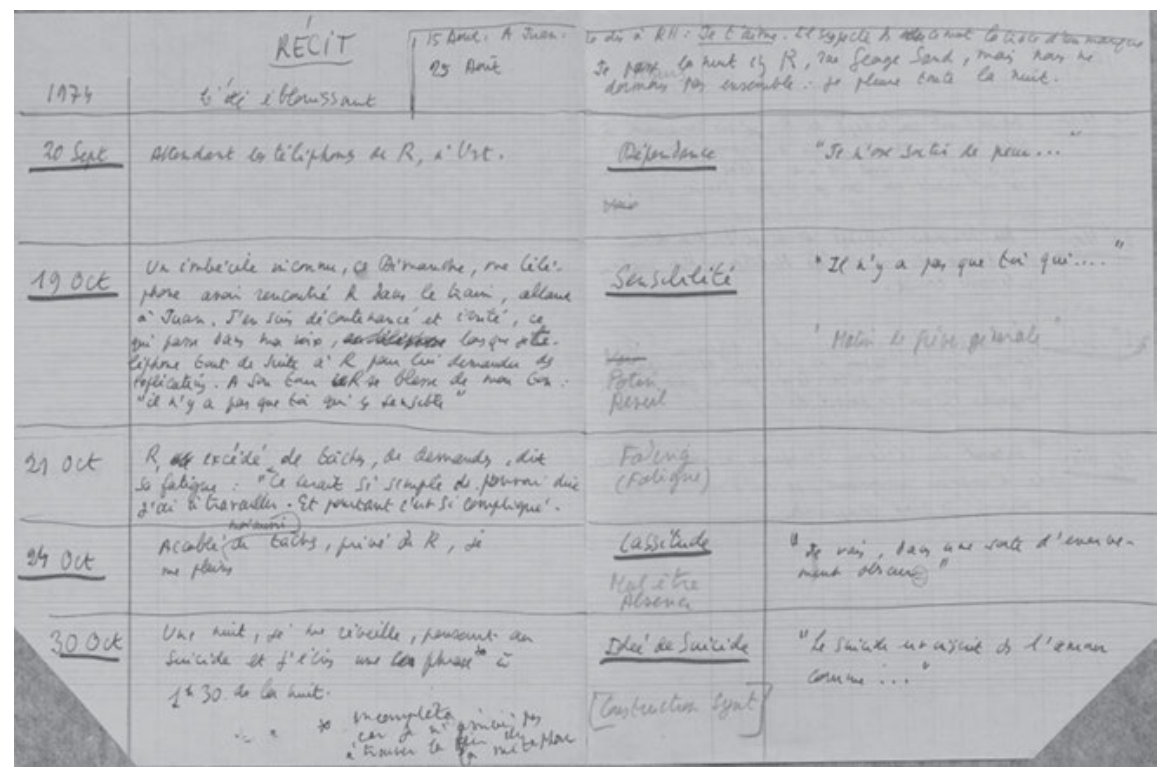

Abb. 23: Notizen zur Vorbereitung der Fragments d'un discours amoureux: Chronologisches Notizheft.

Der erwähnte, den Umschlag des Bandes gestaltende Ausschnitt aus einem Gemälde macht bereits auf der Ebene des Paratextes das Fragmentarische, das vom Titel des Buches angekündigt wird, anschaulich. Alle Teile dieses Textes sind aufs Engste miteinander verwoben und versuchen stets, eine literarischkünstlerische Ebene mit einer deutlich metatextuellen Dimension zu verknüpfen.

Wie schon bei Roland Barthes par Roland Barthes wird auch bei diesem Buch auf die Gestaltung der paratextuellen Elemente große Sorgfalt verwendet. Sie ist bei den Büchern von Roland Barthes stets zentral, werden doch paratextuell bestimmte Lektüremuster und Lesarten vorgegeben oder zumindest nahegelegt. Dem Titel des Bandes kommt dabei eine große Wichtigkeit zu. Dies betrifft nicht nur die bereits erwähnte Benutzung des Begriffes „Diskurs“, die wir ja schon erörtert haben. Der Titel signalisiert auch, dass es nicht um den Liebesdiskurs 
schlechthin, sondern um einen Diskurs (eben dieses einen Liebenden) geht. Das Ich ist singulär und doch aus verschiedensten Quellen gespeist: Gerade darin besteht seine Individualität und zugleich seine Repräsentativität für das Menschliche überhaupt, für die großen Gefühle des Menschen.

Diese Singularisierung besitzt aufgrund der Einstreuung von Biographemen Barthes' einen personalisierenden Effekt, der sich auf den Autor des Buches selbst richtet. Die Formen des Autobiographischen waren mit Roland Barthes par Roland Barthes noch längst nicht erschöpft. Schon der Titel des Fragments lässt eine autobiographische Lesart zu, ohne sie doch zu bestätigen. Man könnte daher sehr wohl in ihnen eine Fortsetzung der Autobiographie (mit anderen Textmitteln) erblicken, die durchaus nicht weniger experimenteller Natur als in Roland Barthes par Roland Barthes ist. So kommt dem Titel eine die Strukturierung des gesamten Bandes bereits ankündigende Funktion zu. Von großem Gewicht ist aber auch das, was Barthes in seiner 1973 vorgelegten Analyse einer Erzählung Poes recht anschaulich als die „aperitive Funktion“ des Titels bezeichnete: Der Text sei eine „Ware“ und es komme darauf an, „beim Leser den Appetit anzuregen“33. Genau dies gelingt Barthes mit dem Zusammenspiel von Titel, Autorname und Bildfragment bereits auf der ersten Umschlagseite. Die gesamte Komposition ist appetitanregend und verspricht bei ausgedehnter Lektüre noch mehr.

Roland Barthes' Arbeit am Paratext setzt sich auf der vierten Umschlagseite fort. Auf der U4 wird dem Leser ein Schriftbild präsentiert, in dem er eine menschliche Figur, aus Buchstaben gemacht, erkennen kann. Es wird von einer Reihe kurzer, alphabetisch angeordneter Ausdrücke gebildet, in deren „Zentrum“ das in seiner Zeile allein stehende Je-t-aime steht und lockt. Barthes hat hier als optischen Blickfang jene Stichworte angeordnet, denen die einzelnen Fragmente des Liebesdiskurses zugeordnet sind. Sie werden im Buch selbst als „Figuren“ beziehungsweise als „Argumente“ bezeichnet. Die einzelnen Figuren bilden dergestalt eine Gesamtheit, eine wohldurchdachte Figuration.

Die Gesamtstruktur des Buches ist - sagen wir es vorsichtig - ungewöhnlich. Denn der eigenwillige Semiologe hat seine Fragmente in eine Abfolge voneinander abgetrennter Figuren der Liebe oder des liebenden Subjekts (denn das Geschlecht des „Ich“ ist nicht durchgängig determiniert) eingeteilt, um auf diese Weise jegliche Geschichte, jegliche Narration zu vermeiden. Der Diskurs der Liebe, der „heute von einer extremen Einsamkeit“"34 sei, wird nicht narrativ erlöst:

33 Barthes, Roland: Roland Barthes par Roland Barthes. In (ders.): Oeuvres complètes, Bd. II, S. 1657.

34 Barthes, Roland: Fragments d'un discours amoureux, S. 5. 

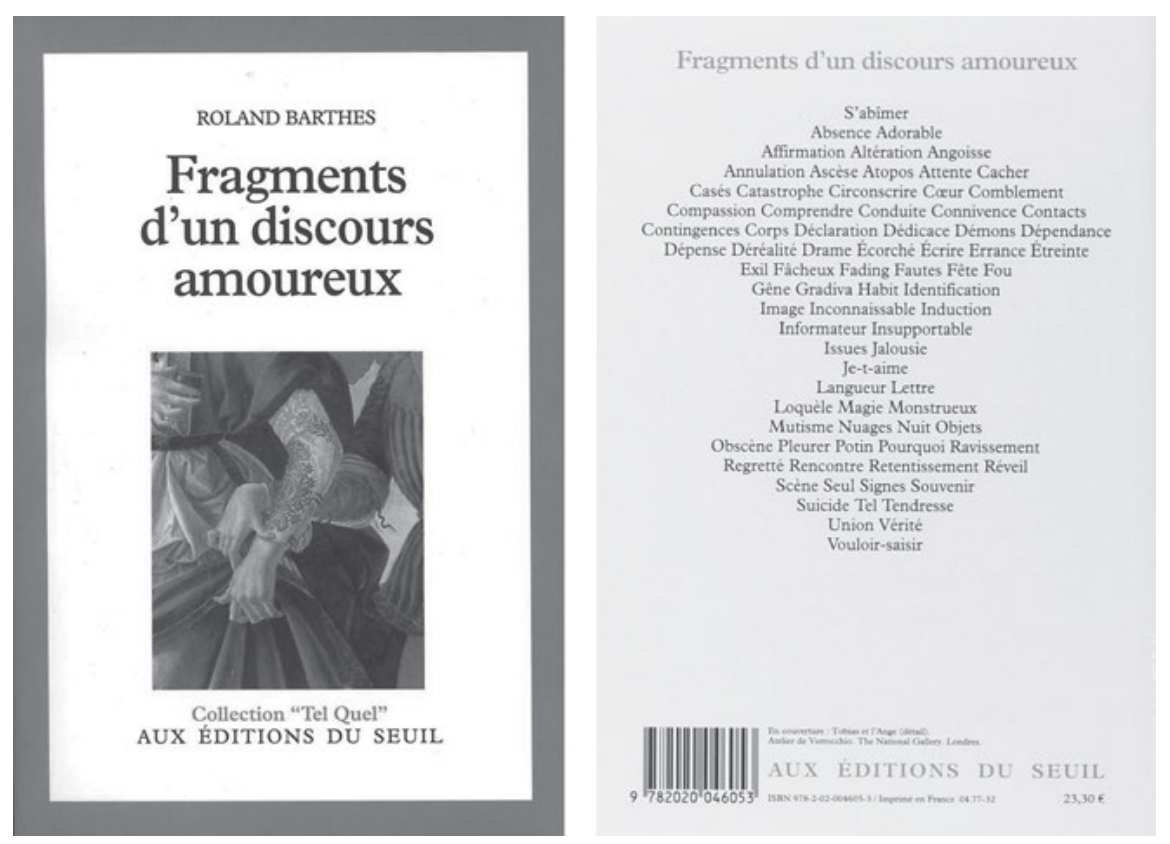

Abb. 24a und b: Cover und Klappentext der Originalausgabe von Roland Barthes' Fragments d'un discours amoureux.

Wir haben keine Love Story vor uns. Das liebende Subjekt bleibt auf sich selbst zurückgeworfen, ohne dass dies doch zu einer psychologischen Tiefendimension des Liebenden führen würde: „Die Einsamkeit des Liebenden ist keine Einsamkeit einer Person (die Liebe wird gestanden, spricht, wird erzählt), es ist eine Einsamkeit des Systems““. ${ }^{35}$ Dies überrascht dann doch: Denn ist das liebende Subjekt wirklich in seiner Einsamkeit gefangen? Ist die Liebe nicht so oft eine Flucht aus der Einsamkeit in eine wie auch immer möblierte Zweisamkeit?

Die Vereinzelung des Liebessubjekts erweist sich als „eine ,philosophische“ Einsamkeit, da die Liebe als Leidenschaft heute von keinem größeren Denksystem einbezogen“ werde. ${ }^{36}$ So ist das liebende Subjekt gleichsam soziodiskursiv in absoluter Einsamkeit gefangen, gleichviel, ob es sich dessen bewusst ist oder nicht. Der Diskurs des oder der Liebenden wird von keiner Philosophie, weder christlicher noch marxistischer Herkunft, gestützt und abgesichert. Die entsprechenden Figuren des Textes lassen daran keinerlei Zweifel aufkommen: 
Die Einsamkeit des Liebenden ist keine Einsamkeit der Person (die Liebe vertraut sich an, sie spricht, sie teilt sich mit), sie ist Einsamkeit des Systems: ich bin der einzige, der sie zum System macht (vielleicht deshalb, weil ich unaufhörlich auf den Solipsismus meines Diskurses zurückgeworfen werde). Schwieriges Paradoxon: ich kann von jedermann verstanden werden (die Liebe kommt aus Büchern, ihr Dialekt ist geläufig), aber gehört (,prophetisch“ aufgenommen) werden nur von Subjekten, die hier und jetzt genau die gleiche Sprache sprechen wie ich. Die Liebenden, sagt Alkibiades, sind den von einer Schlange Gebissenen ähnlich: „Denn man sagt ja, wem dies begegnet sei, der wolle niemandem sagen, wie ihm gewesen, als den ebenfalls Gebissenen, weil diese allein verstehen und verzeihen könnten, was einer auch alles getan und geredet hat vor Schmerz“ [...]. ${ }^{37}$

Wir sind gleichsam in einem Netz von Verweisen, in einem Garten der Pfade, die sich verzweigen, intertextuell aufgehoben (in einem doppelten Wortsinne). Sie sehen an dieser Passage, wie Roland Barthes aus der Position des Liebenden die Figur der Einsamkeit thematisiert und - hier etwa im Rückgriff auf Alkibiades, wenig später auf den von ihm so oft herbeizitierten Mystiker Ruysbroeck anhand von eingewobenen Beispielen vorführt oder ausagiert. Wir sehen auch schon an diesem kleinen Beispiel die komplexen Paradoxien, die den gesamten Text auffällig durchziehen. Denn diese Paradoxien erlauben es Roland Barthes, sich jeweils einer Doxa zu entziehen. Sie werden nur dadurch plastisch vor Augen geführt, insofern sie von verschiedenen Stimmen und Positionen aus vorgetragen werden und doch immer wieder das sujet amoureux fokussieren. Der Liebesdiskurs der Fragments d'un discours amoureux ist polylogisch aufgebaut.

Bereits im orientierenden Vorwort - über die Funktionen des Paratextuellen haben wir ja bereits gesprochen - wird jedoch betont, dass es „monströs“ gewesen wäre, diese Leerstelle mit einer eigenen Philosophie der Liebe zu füllen, ${ }^{38}$ dürfe hier doch nur eine „Affirmation“, ${ }^{39}$ eine Bejahung und Bekräftigung erwartet werden. An dieser Bekräftigung der Liebe fehlt es wahrlich nicht - und die Literaturen der Welt sind voll davon. Das Ich erscheint wie eine Echokammer, in welcher all diese Stimmen widerhallen. Hingegen wird nicht nur die Erzählung, sondern auch die Metasprache, auf der jegliches philosophisches System beruht, sorgfältig vermieden. Roland Barthes gibt sich damit erneut seiner Liebe zur Sprache in Fragmenten hin und vermeidet es, seine Liebesfragmente und Liebesbekräftigungen mit einer Philosophie der Liebe zu überhöhen. Damit bleibt die viellogische Strukturierung des Bandes erhalten. Doch wie ist diese Polylogik, wie ist diese Polyphonie musikalisch instrumentiert?

37 Barthes, Roland: Fragmente, S. 35.

38 Barthes, Roland: Fragments d'un discours amoureux, S. 12.

39 Ebda. 
Das von Roland Barthes inszenierte und zum Sprechen gebrachte Subjekt ist aus Bruchstücken literarischer und philosophischer, musikalischer und filmischer, schriftlicher und mündlicher, autobiographischer wie fiktionaler Provenienz montiert. Die Montage ist das eigentliche Signum des Buches. Die dramatische Erfahrung der Machtlosigkeit und Ungeschütztheit des Liebesdiskurses kommt in den insgesamt 80 Figuren im vollen Wortsinn theatralisch zum Ausdruck. Denn es handelt sich um in Szene gesetzte Diskurse. Die Zuordnung der Fragmente zu einer Figur hält diese quasi in einer Serie akausal angeordneter Standbilder fest: Sie sind zugleich Statuen und in ihrer ständigen Bewegung festgehaltene Momentaufnahmen des liebenden Subjekts. Man könnte diese Anlage auch mit einem Mobile vergleichen, in welchem sich die Betrachter und die jeweiligen Figuren ständig bewegen und ihre jeweiligen Bezugspositionen wechseln.

So ist die an den Leser gewandte Erklärung zu verstehen, sie nicht als rhetorische, sondern eher als gymnastische oder choreographische Figuren aufzufassen..$^{40}$ Ein Bewegungsraum ist entstanden, der voller Überraschungen steckt. Diese Choreographie der Liebesfiguren greift auf zwei dem französischen Literatur- und Zeichentheoretiker teure Verbindungen von Körper und Schrift zurück: Erstens auf jene Körper, die sich in den Texten des Marquis de Sade zu rhetorischen Figuren anordneten, die Barthes in Sade, Fourier, Loyola analysierte. Und zweitens sein Rückgriff auf das Alphabet von Erté, dessen grazile und geschmückte Frauenkörper sich in die Graphie der Buchstaben fügen. Körperlichkeit und Bildlichkeit sind den Figuren damit doppelt, auf der Ebene des Textes wie auf der intratextuellen Ebene, eingeschrieben. Sie beginnen sich zu bewegen und bilden jene vielgestaltige Figuration, die sich als ein textuelles Mobile beschreiben lässt.

Diese Bewegung ist zentral. Wie schon in Leçon, Barthes' Antrittsvorlesung am Collège de France, wird der Begriff des Diskurses als eine Bewegung, als ein Hin- und Herlaufen verstanden. Insofern zeichnet bereits dort das zwischen seiner Mutter und irgendwelchen zufällig erblickten Gegenständen hin- und herlaufende Kind die Figuren der Liebe nach. In den Fragmenten eines Diskurses der Liebe, wo die Liebe der beziehungsweise zur Mutter - „der wohltuende Ruf, die Rückkehr der Mutter“41 - gleichfalls präsent ist, ist diese Bewegung jedoch tänzerischer und erinnert an das, was Barthes in seinem 1965 erschienenen Lexikonartikel über „Das griechische Theater“ den Griechen nachsagte: Sie hätten

40 Ebda., S. 7.

41 Ebda., S. 49. 

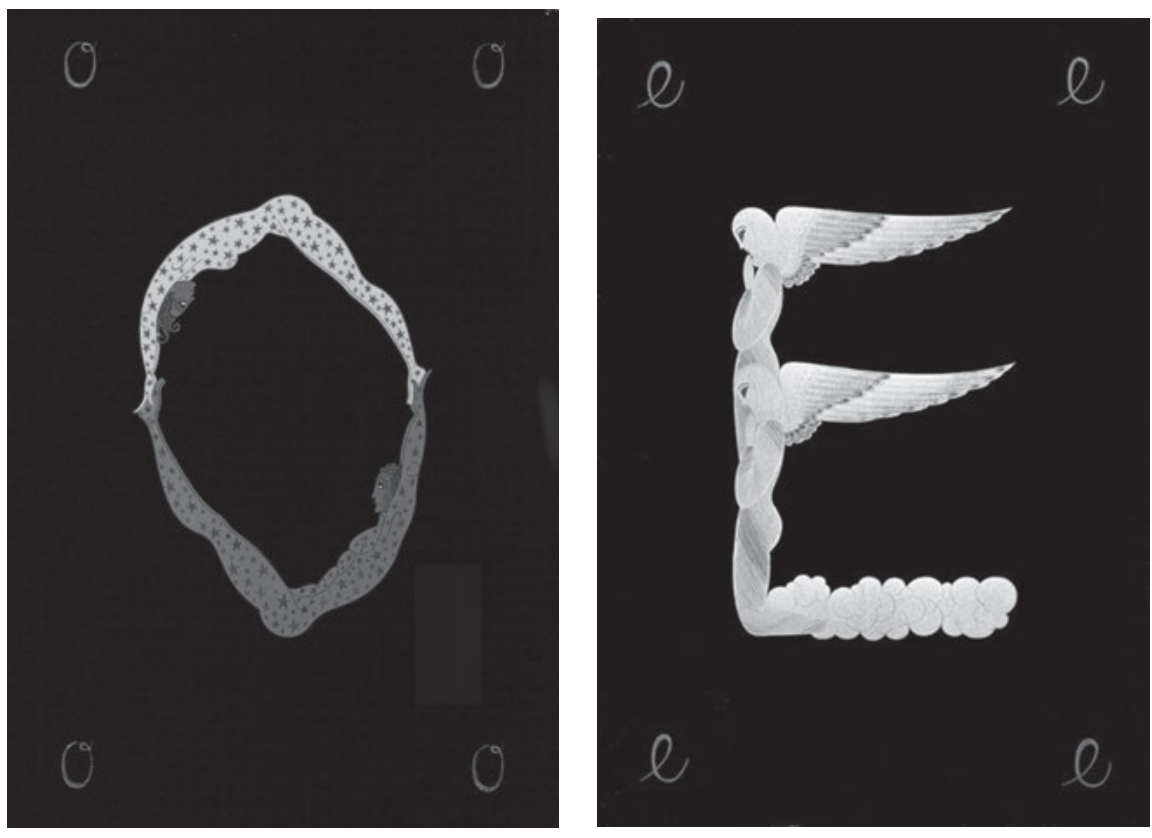

Abb. 25a und b: Alphabet von Erté.

die Figuren oder Schemata des Tanzes als Kodierungen gelesen. ${ }^{42}$ Barthes greift immer wieder auf diese Choreographien - die Choreographien der Liebe sind als Bewegungsfiguren zurück.

In einer im Oktober 1972 in La Quinzaine littéraire erschienenen Rezension von Gérard Genettes Buch Figures III beschrieb Roland Barthes dessen Verständnis von Figuren als „logische[n] Formen, Ausdrucksarten (manières) des Diskurses, deren Feld nicht bloß eine kleine Gruppe von Wörtern, sondern die Struktur des Textes in seiner Gesamtheit“ sei. ${ }^{43}$ Doch vergessen wir nicht die anhaltende Beschäftigung des Zeichentheoretikers seit seinem Michelet mit dem Körper und dessen Körperlichkeit. Denn gegenüber dieser narratologischen, diskursanalytischen Definition zeichnet sich der Barthes'sche Figurbegriff durch seine Körperlichkeit, Plastizität und Sinnlichkeit aus. Auch und gerade die Formen der Wissbegierde und des Wissens sind bei Barthes nicht nur figurativ, sondern erotisch.

42 Barthes, Roland: Oeuvres complètes, Bd. I, 1552.

43 Barthes, Roland: Oeuvres complètes, Bd. II, S. 1433. 


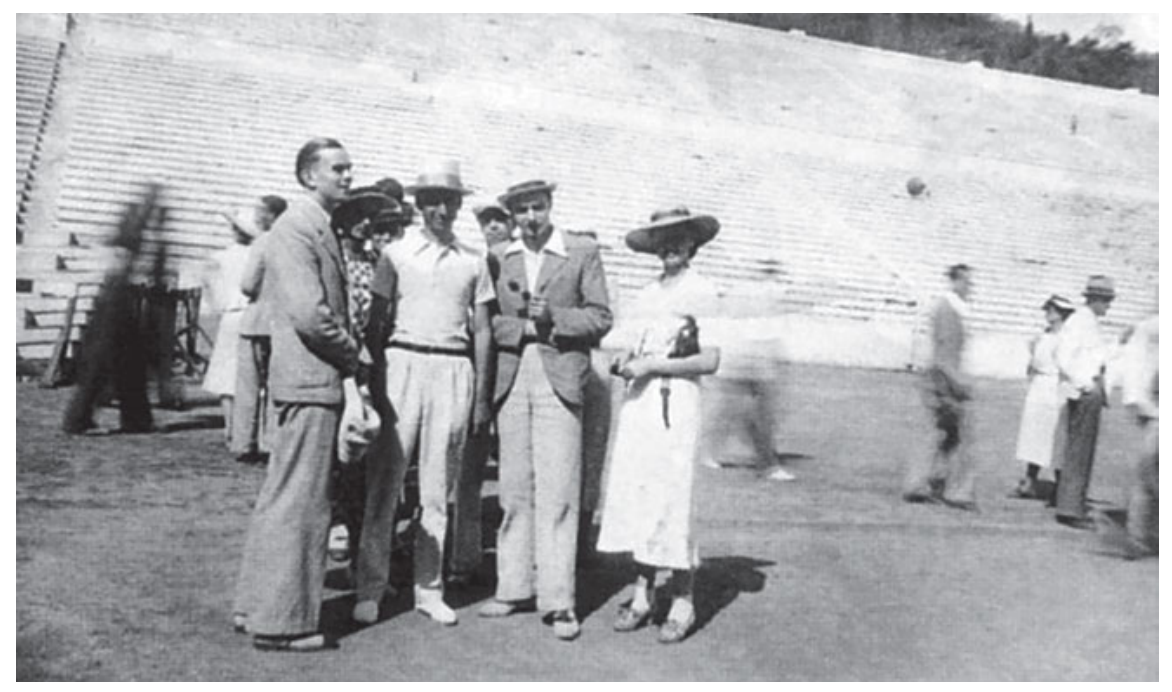

Abb. 26: Roland Barthes mit der „Groupe de théâtre antique de la Sorbonne“ während einer Reise nach Griechenland, Sommer 1938.

Eine „Geschichte der Quellen“, so heißt es in Roland Barthes par Roland Barthes, müsse ersetzt werden durch eine „Geschichte der Figuren“, die in der Folge als Posturen, als Körperstellungen verstanden werden. ${ }^{44}$ Schon in seiner Analyse von Balzacs Novelle in $S / Z$ zeigte Barthes auf, dass auch der Lektüreakt eine Abfolge von Körperstellungen ist, die der Leser dem Text gibt. Nicht umsonst hatte Italo Calvino gleich in seinem incipit von Se una notte d'inverno un viaggiatore ein besonderes Gewicht auf diese Körperstellungen gelegt. Die erotische Dimension dieser Stellungen bedarf keines zusätzlichen Kommentars.

In diesem Sinne sind die Figuren der Fragments Roland Barthes' choreographische Figuren der Liebe, die auch das Lesepublikum in ihr Spiel miteinbeziehen. Es könnte gerade diese leseraktivierende Dimension gewesen sein, die zusätzlich zu den bereits genannten Gründen zum Erfolg der Fragmente eines Diskurses der Liebe weltweit geführt hat. Denn der Text von Barthes berührt seine Leserschaft. In der deutschen Übersetzung wurde nicht - was durchaus problematisch ist - die Abfolge der einzelnen Textfragmente Barthes', sondern das Ordnungsprinzip der alphabetischen Ordnung übernommen, welche im Deutschen selbstverständlich eine ganz neue, andere Sequenz erzeugt. Damit wird zwar die ursprüngliche Ordnung des Bezugstexts zerstört; dafür aber entsteht ein eigener Text, in dem die einzelnen Fragmente, gemäß ihrer neuen deutschsprachigen

44 Barthes, Roland: Roland Barthes par Roland Barthes, S. 103. 
Titel alphabetisch angeordnet, neue Beziehungen eingehen, die belegen, dass auch in den Fragments d'un discours amoureux die Leserichtung auf vielfache Weise umkehrbar ist. Barthes' Text ist insofern durchaus mit einem je eigenen Spiel in andere Sprachen übersetzbar und wurde selbst ins Chinesische übertragen.

Noch einmal zur Frage, wie der Band gemacht ist. Die einzelnen Figuren sind innerhalb des Textes stark untergliedert, so dass - ähnlich wie in $S / Z$ - eine recht komplexe graphische (beziehungsweise grammatextuelle) Strukturierung des Schriftbilds ins Auge fällt. Grundlegend ist Barthes’ Kurzschreibweise, seine écriture courte. Jeder Überschrift (oder „Figur“) folgt ein „Argument“, das im Gewand der Definition in ein Wechselspiel mit dem Titel der jeweiligen Figur, aber auch mit den nachfolgenden, zur Figur gehörenden durchnummerierten Fragmenten tritt. Allen drei Bestandteilen einer figure sind unterschiedliche Schriftgrößen zugeordnet, welche die Gesamtfiguren untergliedern. Hinzu kommt, dass - wie in Lehrbüchern - Bezugstexte in einer Kommentarkolonne neben den Fragmenten aufgeführt werden, so dass der Leser den jeweiligen Gesprächspartner beziehungsweise Intertext leicht ausfindig machen und zuordnen kann. Durch Fußnoten werden zusätzliche, graphisch abgesetzte Verweise gegeben.

Dieses Verfahren führt zu einem recht komplexen Aufbau der einzelnen Figuren, wobei Titel, Argumente und Fragmente oft in einen Kontrast gebracht werden, der auf die Willkür der Benennungen aufmerksam macht. Dem produktiven Zufall wird dabei viel Spielraum gegeben. So entspricht zwar der Figur „Geisterschiff“ das Argument „Herumirren“; doch werden etwa den Figuren „Laetitia“ beziehungsweise „Unaussprechliche Liebe“ als Argumente „Eingrenzen“ beziehungsweise „Schreiben“ an die Seite gestellt. Immer wieder überschneiden sich dabei auch die für unsere Vorlesung zentralen Themenbereiche von Liebe und Lesen, wobei diese Konstellation im Sinne der vom „Ich“ gelesenen intertextuellen Bezüge ohnehin grundlegend ist. Nicht nur die zahlreichen Zitate, sondern auch die semantischen, diskursiven und graphischen Brüche signalisieren die bewusste Fragmentierung nicht allein des Textes oder des Diskurses der Liebe, sondern auch des liebenden Subjekts selbst. Denn gerade auch das liebende „Ich“ ist von der fundamentalen Fragmentierung aller Dinge und aller Diskurse erfasst. Es ist ein zerklüftetes, gespaltenes Ich, ganz so, wie wir es in unserem Zitat aus Le Plaisir du texte bereits gesehen haben.

Es entsteht auf diese Weise ein künstlerisches Figurenfeld, das sich einer strikten Klassifizierbarkeit ebenso entzieht wie einer notwendig einzuhaltenden Leserichtung. Es ist die „Ordnung“ eines Mobile. Die Beziehungen sind variabel, bilden ständig sich wandelnde Konstellationen. An die Stelle der Ordnung tritt die Anordnung. Die Leserinnen und Leser können zwischen den einzelnen 


\section{"Je m’abîme, je succombe..."}

s'ABÎMER. Bouffée d'anéantissement qui vient au sujet amoureux, par désespoir ou par comblement.

1. Soit blessure, soit bonheur, il me prend parfois l'envie de m'abîmer.

Ce matin (à la campagne), il fait gris et doux. Je souffre (de je ne sais quel incident). Une idée de suicide se présente, pure de tout ressentiment (aucun chantage à personne); c'est une idée fade; elle ne rompt rien (elle ne "( casse ) rien), s'accorde à la couleur (au silence, à l'abandon) de cette matinée.

Un autre jour, sous la pluie, nous attendons le bateau au bord d'un lac; de bonheur, cette fois-ci, la même bouffée d'anéantissement me vient. Ainsi, parfois, le malheur ou la joie tombent sur moi, sans qu'il s'ensuive aucun tumulte : plus aucun pathos : je suis dissous, non dépiécé; je tombe, je coule, je fonds. Cette pensée frôlée, tentée, tâtée (comme on tâte l'eau du pied) peut revenir. Elle n'a rien de solennel.

Ceci est très exactement la douceur.

WERTHER : « En ces pensées, je m'abîme, je succombe, sous la puissance de ces magnifiques visions " (4). "Je la verrai [...] Tout, oui, tout, comme englouti par un abîme, disparaît devant cette perspective " (43).

Abb. 27a und b: Seitenlayout der ersten Seiten von Roland Barthes' Fragments d'un discours amoureux, S. 15-16. 


\section{S'abîmer}

2. La bouffée d'abîme peut venir d'une blessure, mais aussi d'une fusion : nous mourons ensemble de nous aimer : mort

Tristan

Baudelaire ouverte, par dilution dans l'éther, mort close du tombeau commun.

L'abîme est un moment d'hypnose. Une suggestion agit, qui me commande de m'évanouir sans me tuer. De là, peut-être,

Rusbrock la douceur de l'abîme : je n'y ai aucune responsabilité, l'acte (de mourir) ne m'incombe pas : je me confie, je me transfère (à qui ? à Dieu, à la Nature, à tout, sauf à l'autre).

3. Lorsque ainsi il m'arrive de m'abîmer, c'est qu'il n'y a plus de place pour moi nulle part, même pas dans la mort. L'image de l'autre - à quoi je collais, de quoi je vivais - n'est plus; tantôt c'est une catastrophe (futile) qui semble l'éloigner à jamais, tantôt c'est un bonheur excessif qui me la fait rejoindre; de toute manière, séparé ou dissous, je ne suis recueilli nulle part; en face, ni moi, ni toi, ni mort, plus rien à qui parler.

(Bizarrement, c'est dans l'acte extrême de l'Imaginaire amoureux - s'anéantir pour avoir été chassé de l'image ou s'y être confondu - que s'accomplit une chute de cet Imaginaire : le temps bref d'un vacillement, je perds ma structure d'amoureux : c'est un deuil factice, sans travail : quelque chose comme un non-lieu.)

TRISTAN : " Dans le gouffre béni de l'éther infini, dans ton âme sublime, immense immensité, je me plonge et m'abîme, sans conscience, ô volupté! 》 (Mort d'Isolde).

BAUDELAIRE : " Un soir fait de rose et de bleu mystique, Nous échangerons un éclair unique, Comme un long sanglot, tout chargé d'adieux " (la Mort des amants).

RUSBROCK : « ... le repos de l'abîme " (40).

\section{6}

Abb. 27a und b (fortgesetzt) 


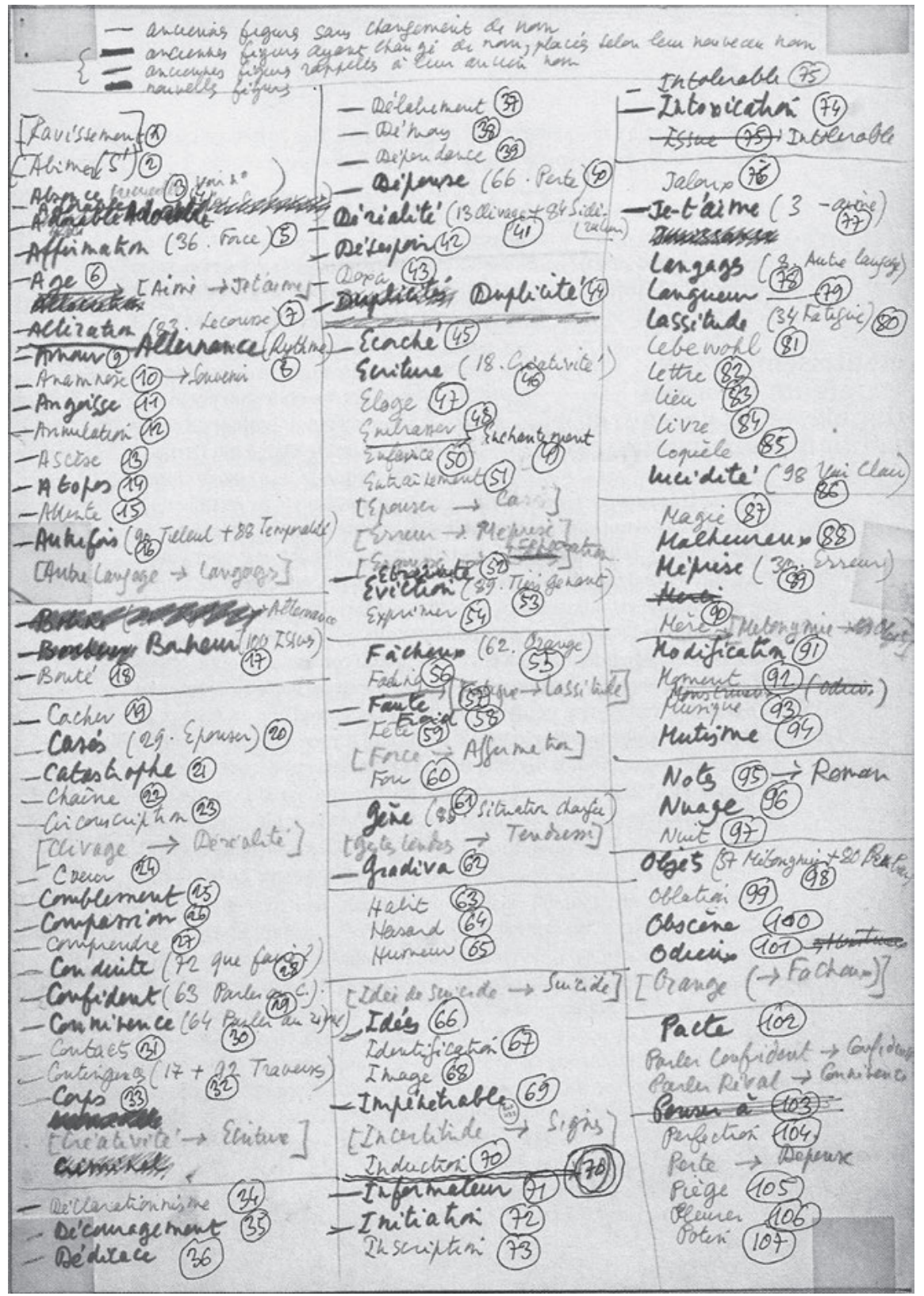

Abb. 28: Notizen zur Vorbereitung der Fragments d'un discours amoureux: Index der Figuren. 
Figuren hin- und herspringen und damit dem Text eigene Figuren, eigene postures übertragen. Es steht der Leserschaft frei, aus den Fragmenten eine Philosophie der Liebe abzuleiten; das Buch selbst entwickelt eine solche Philosophie nicht, ja vermeidet sie akribisch. Jeglicher Systemcharakter wird dekonstruiert oder, wie man noch besser sagen könnte, choreographiert, in Figuren und Körperkonstellationen aufgelöst. Alles, einschließlich des Lesepublikums, ist in Bewegung.

Freilich könnte man gerade dies wiederum als eine andere Philosophie der Liebe interpretieren. Denn wäre nicht gerade auch aus der Mobilität, aus der Beweglichkeit aller Faktoren, aller Subjekte eine solche Philosophie abzuleiten? Ein logisches und kausal aufgebautes Denksystem lässt sich aus den Fragments d'un discours amoureux aber nicht errichten. Die Liebe entzieht sich - zumindest deuten dies die Fragmente mit ihren jeweiligen Figuren an - jeglicher diskursiver Herrschaft über sie. Die Liebe steht mit dem Körper und mit dem Leib, mit dem Lesen und mit der Lust im Bunde.

Die Figuren des Liebestänzers gehorchen - durchaus in einem an Friedrich Nietzsche geschulten Sinne - ihrer jeweils eigenen Logik. Sie tauchen im Kopf jedes Subjekts ohne erkennbare Ordnung nacheinander auf:

Bei jedem dieser Zwischenfälle (das, was ihn „überfällt“, „,befällt“) schöpft der Liebende aus dem Vorrat (dem Schatz?) der Figuren, je nach den Bedürfnissen, den Weisungen oder den Lüsten seines Imaginären. Jede Figur blitzt auf, vibriert allein wie der aus einer Melodie herausgelöste Klang - oder wiederholt sich bis zum Überdruss wie das Motiv einer in sich kreisenden Musik. ${ }^{45}$

Dies erinnert uns an die Lektüre des Körpers der und des Geliebten in Italo Calvinos Lese- und Liebesroman. Barthes selbst mochte sehr wohl an seine marokkanischen Incidents gedacht haben, die er 1969 in seiner Zeit im Maghreb niedergeschrieben hatte. Dort war die Lektüre des anderen mit einer Lektüre des eigenen Körpers verbunden worden und hatte $\mathrm{zu}$ einer rationalen Erklärungsmustern nicht mehr zugänglichen Logik geführt. Im Anderen haben wir den Körper als ein Objekt vor uns, das doch urplötzlich zum Leib wird, während sich unser eigener Leib in einen Körper verwandelt.

Die Incidents von Roland Barthes lassen sich zweifellos als ein Buch der Fragmente einer homosexuellen Liebe lesen, als einen Band, dessen Erscheinen sein Autor zu Lebzeiten seiner Mutter nicht wünschte. Diese Konstellation von Körper-Haben und Leib-Sein findet sich auch in den Fragmenten eines Diskurses der Liebe. Im Buch von 1977, das sich ebenfalls einer fragmentarischen, aber

45 Barthes, Roland: Fragments d'un discours amoureux, S. 10. 
wesentlich komplexer strukturierten Schreibweise bedient, ist die Dimension der Körperlichkeit jedoch in weit vielfältigerer Weise gegenwärtig, wobei auch hier der homosexuellen Liebe (wenngleich viel diskreter) eine wichtige Funktion im Sprechen des liebenden Subjekts zukommt. Denn die Liebe ist hier nicht heterosexuell oder homosexuell oder wie auch immer geschlechtlich denkbar determiniert.

Das oben angeführte Zitat belegt gleichfalls, dass der Körper des liebenden Subjekts auch durch die Dimension, die Vibrationen und Schwingungen der Musik repräsentiert wird. Nicht umsonst hatte Barthes den letzten Teil seiner „Tabula gratulatoria“ vor allem den Komponisten und damit der von ihm so sehr geschätzten und geliebten Musik vorbehalten. So stoßen im Diskurs der Liebe die verschiedensten Logiken aufeinander, ohne doch auf eine einzige Logik reduzierbar zu sein. Der discours amoureux erscheint als zutiefst paradoxer Diskurs, der nicht einer bestimmten Logik - auch nicht der Körperlogik - überantwortet werden kann und keiner Doxa unterliegt. Er entzieht sich der Macht und jeglichem System, das sich seiner bemächtigen und ihn sich gefügig machen könnte.

Sein Ende findet er erst dort, wo der Diskurs, wo die Sprache endet: in der geschlechtlichen Vereinigung. ${ }^{46}$ So heißt es in der Figur étreinte (Umarmung) eindringlich:

Außer der eigentlichen geschlechtlichen „Paarung“ (zum Teufel dann mit dem Imaginären) gibt es jene andere Art von Umarmung, die reglose Umschlingung: wir sind verzaubert, betört: wir liegen im Schlaf, ohne zu schlafen; wir sind in der kindlichen Wonne des Einlullens befangen: das ist der Augenblick des Geschichtenerzählens, der Augenblick der Stimme, die mich bannt, mich entrückt, es ist die Heimkehr zur Mutter (,im sanften Frieden deiner Arme“, sagt ein von Duparc vertontes Gedicht). In diesem verlängerten Inzest ist dann alles außer Kraft gesetzt: die Zeit, das Gesetz, das Verbot: nichts müht sich ab, nichts wird gewollt: alle Begierden sind aufgehoben, weil sie endgültig gestillt scheinen. ${ }^{47}$

Dies ist die Figur einer völligen Erfüllung, die auch eine Vereinigung mit der Mutter und damit die Umgehung des Inzesttabus beinhaltet. Doch alle Wünsche, alle Begierden scheinen nur endgültig gestillt. In dieser Passage findet sich eine Vielzahl von Elementen, die sich hier zur Umarmung zusammenfinden, im Grunde aber auch auf eine von Barthes nicht genannte Figur - jene der Ewigkeit - anwendbar wären. Denn wie schon Nietzsche sagte: „Denn alle Lust will Ewigkeit, [...] will tiefe, tiefe Ewigkeit.“48

46 Barthes, Roland: Fragments d'un discours amoureux, S. 121.

47 Barthes, Roland: Fragmente, S. 214.

48 Nietzsche, Friedrich: Also sprach Zarathustra, Bd. 4. Leipzig: Druck und Verlag von C. G. Naumann 1891, S. 129. 
Bei Barthes steht immer wieder die Mutter im Mittelpunkt des Liebesdiskurses wie jeglichen Diskurses, und selbstverständlich ist damit dann auch das Geschichtenerzählen und letztlich der Roman und die Literatur verbunden. Die Umschlingung steht so in einem eigenartigen Spannungsverhältnis zur Umarmung in den Liebespositionen, zur körperlichen Vereinigung des Liebespaares, in welcher der Körper-Leib nun spricht, der Diskurs aber zu einem Ende gekommen scheint. Nur scheint: Denn auch diesem Augenblick nähert sich Barthes diskursiv an.

Italo Calvino hatte noch von den verschiedenen anderen armseligen Alphabeten gesprochen, mit deren Hilfe sich die Menschen wechselseitig zu lesen glauben. Das Schreiben des Liebenden hintergeht die Mode, ist „altmodisch“ und „anachronistisch im Verhältnis zum modernen Text“.49 Damit wird ein Motiv aufgenommen, das schon im ersten Satz des Vorworts anklang: Es geht darum, „das hören zu lassen, was in seiner Stimme an Unzeitgemäßem, das heißt an Unbehandelbarem mitschwingt“. ${ }^{50}$ Auch dies ist unverwechselbar nietzscheanisch geprägt, von einem literarischen Philosophieren also, das die Unzeitgemäßheit zum Programm erhob.

Roland Barthes versucht, das Unzeitgemäße und Altmodische - in seinem Sinne etwa die Musik von Schumann und Schubert - gegen das Modische und Moderne auszuspielen, um daraus eine neue Aktualität zu gewinnen. Der „moderne Text“, dies hatte er schon 1972 festgestellt, führe sein eigenes Zerbersten in verschiedenste Fragmente herbei; da könne man den „alten Text“ durch eine neue Lektüre viel effektvoller zur Explosion bringen: „Je älter ein Text ist, umso besser explodiert er“.51 Damit ist zugleich die Freiheit der Lektüre, die Freiheit des Lesepublikums zuungunsten einer ehemals vorherrschenden Autorschaft gemeint. der Leser steht im Fokus - auch und gerade in der Verschmelzung von Leseakt und Liebesakt.

Eine Reihe von Tagebuchaufzeichnungen aus dieser Zeit, die Barthes 1979 noch einmal in Tel Quel veröffentlichte, führen eindringlich vor Augen, wie er im Jahr seiner großen Erfolge ständig zwischen Angst und Hoffnung schwankte: „Dunkle Gedanken, Ängste, Angstzustände: ich sehe den Tod des teuren Wesens“.52 „Mam geht es heute besser. Sie sitzt im Garten, mit einem großen Strohhut." ${ }^{33}$ Doch alles Bangen und Hoffen half letztlich nicht: Henriette Barthes verstarb am 25. Oktober 1977. Barthes' Journal de deuil legte nicht allein

49 Barthes, Roland: Fragments d'un discours amoureux, S. 112.

50 Ebda., S. 7.

51 Barthes, Roland: Oeuvres complètes, Bd. II, S. 1431.

52 Barthes, Roland: Le bruissement de la langue. Essais critiques IV. Paris: Seuil 1984, S. 402.

53 Ebda., S. 404. 
von der tiefen Trauer ihres Sohnes ein beredtes Zeugnis ab; der postum veröffentlichte Band ist auch so etwas wie ein lebendiger Grabstein für die Liebe zu seiner Mutter. Das Nachdenken über den Tod, das sich in der zweiten Hälfte der siebziger Jahre bereits verstärkt hatte, erhielt nun eine gänzlich andere, bittere Färbung. Seine Fragments d'un discours amoureux blieben davon unberührt und zeugen von der noch heiteren Ars amatoria des Roland Barthes.

Wir könnten an dieser Stelle weiterverfolgen, wie sich nun der Komplex der Mutterliebe im Schreiben von Barthes in ein Spiel zwischen Leben, Liebe und Tod verwandelt, das 1980, in seinem Todesjahr, seinen Höhepunkt mit der Veröffentlichung von La Chambre claire finden sollte. Doch möchte ich noch etwas bei Barthes' Fragments d'un discours amoureux verweilen, um im Sinne unserer Themenstellung besser zu verstehen, wie seine einzelnen Figuren aufgebaut sind und welchen narrativen Kernen oder choreographischen Bewegungen sie sich widmen. Denn wir haben die Polylogik dieses Textes bei Weitem nicht ausgeschöpft.

Ich hatte bereits die Rückseite des Bandes erwähnt, auf der die insgesamt achtzig Figuren aufgeführt sind und menschliche Gestalt in Buchstabenform annehmen. In der deutschsprachigen Übersetzung lassen sie sich wie folgt in der zufälligen alphabetischen Reihung zusammenfassen:

Abhängigkeit, Abwesenheit, Allein, Anbetungswürdig, Angst, Askese, Atopos, Auswege, Begegnung, Beiläufigkeiten, Bejahung, Berührungen, Betretenheit, Bild, Brief, Dämonen, Drama, Eifersucht, Einbezogen, Einverständnis, Entstellung, Entwertung, Entwirklichung, Erfüllung, Erwachen, Erwartung, Exil, Fading, Fehler, Fest, Gedenken, Gradiva, Habenwollen, Hautlos, Herz, Hingerissenheit, Ich-liebe-Dich, Identifizierung, Induktion, Katastrophe, Klatsch, Kleidung, Körper, Lästig, Liebeserklärung, Magie, Mitleid, Mittelsperson, Monströs, Nachklang, Nacht, Objekte, Obszön, Redeseligkeit, Schreiben, Schweifen, Sehnen, Selbstmord, So, Stummheit, Szene, Umarmung, Umschreiben, Unbegreiflich, Unerträglich, Verausgabung, Verbergen, Vereinigung, Verhalten, Vermißt, Verrückt, Verstehen, Wahrheit, Warum, Weinen, Wolken, Zärtlichkeit, Zeichen, Zueignung, Zugrundegehen. ${ }^{54}$

\section{Im französischen Original:}

S’abîmer Absence Adorable Affirmation Altération Angoisse Annulation Ascèse Atopos Attente Cacher Casés Catastrophe Circonscrire Coeur Comblement Compassion Comprendre Conduite Connivence Contacts Contingences Corps Déclaration Dédicace Démons Dépendance Dépense Déréalité Drame Ecorché Ecrire Errance Etreinte Exil Fâcheux Fading Fautes Fête Fou Gêne Gradiva Habit Identification Image Inconnaissable Induction Informateur Insupportable Issues Jalousie Je-t-aime Langueur Lettre Loquèle Magie Monstrueux

54 Barthes, Roland: Fragmente, Klappentext. 
Mutisme Nuages Nuit Objets Obscène Pleurer Potin Pourquoi Ravissement Regretté Rencontre Retentissement Réveil Scène Seul Signes Souvenir Suicide Tel Tendresse Union Vérité Vouloir-saisir. ${ }^{55}$

Diese Sequenz mag Ihnen eine Vorstellung von der Ausrichtung des Bandes geben und von der Vielfalt seiner Themen, die wirklich ein breites Spektrum an Liebeserleben und Liebeserfahrungen abdecken. Die einzelnen Figuren lassen sich in unterschiedlichste Abfolgen bringen, wie auch ein Vergleich zwischen der Aufeinanderfolge im französischen und im deutschen Text zeigt, welche aufgrund des Alphabets voneinander grundverschieden ist. Im Zentrum des von Buchstaben gebildeten Körperbildes freilich steht das berühmte Wort Je-t-aime, in etwas ungewöhnlicher Schreibung, gleichsam eine Symmetrie in der Figur des Zentrums zum Ausdruck bringend. Ist der Liebesschwur, die Liebeserklärung oder auch die Liebesbehauptung aber nicht selbst in eine komplexe Liebesrhetorik eingebettet, die uns der Band Stück für Stück erläutern wird?

Nun, es handelt sich beim französischen „Ich-liebe-Dich“ um eine recht umfangreiche, nicht weniger als zehn Seiten einnehmende Figur. Dabei gehe es bei dieser Formel nicht um die Liebeserklärung im eigentlichen Sinne, so erfahren wir, denn diese sei gleich schon nach dem ersten Mal verbraucht. Insoweit würde ich-liebe-dich dann nichts mehr sagen oder zum Ausdruck bringen. Hier geht es vielmehr um das Je-t-aime als Liebesschrei, als cri d'amour des einsamen, liebenden Ich. Im Rückgriff auf Lacan betont Barthes' Liebender, dass dieses Wort eigentlich nichts sagen wolle, sondern eine Situation meine, in der das Subjekt einer Spiegelbeziehung zum Anderen ausgesetzt ist. ${ }^{56}$

Die verschiedenen Fragmente, die sich dem Je-t-aime widmen, beleuchten sehr unterschiedliche Aspekte, von denen ich einen Teil, welcher dem neunten Fragment entstammt, etwas genauer unter die Lupe nehmen möchte. Sehen wir uns dies einmal näher an, denn wir können hier eine neue Perspektive auf die gängigste unter allen Liebesformeln einnehmen:

Daraus ergibt sich eine neue Sicht des ich-liebe-dich. Es ist kein Symptom, es ist Aktion. Ich spreche, damit du antwortest, und die gewissenhafte Form der Antwort (der Brief) bekommt einen effektiven Wert, nach Art einer Formel. Es reicht also nicht aus, daß der andere mir mit einem einfachen Signifikat antwortet, und sei es positiv (,ich auch“): das angesprochene Subjekt muß sich bereitfinden, das ich-liebe-dich, das ich ihm entbiete, zu formulieren, auszusprechen [...]; ich will die Formel, den Archetypus des Liebeswortes bekommen, mit einem Schlage, ganz, buchstäblich, ohne Ausflucht: keine syntaktische Ausrede, keine Variation: ich will, daß die beiden Worte einander ohne Rest entsprechen, Signifikant für

55 Barthes, Roland: Fragments d'un discours amoureux, Klappentext.

56 Barthes, Roland: Fragments d'un discours amoureux, S. 137. 
Signifikant zusammenfallen [...]; worauf es ankommt, ist die physische, körperliche, labiale Aussprache des Wortes: öffne die Lippen, damit es hörbar wird (sei obszön). Was ich hartnäckig will, ist: das Wort bekommen [...]; der Fliegende Holländer irrt auf der Suche nach dem Wort umher; wenn er es bekommt (durch Treueeid), hat seine Unstetigkeit ein Ende (was im Mythos zählt, ist nicht die Empirie der Treue, sondern ihre Proferation, ihr Gesang). ${ }^{57}$

Es ist fast, als hätten wir es mit einem Fetisch-Wort zu tun. In dieser Passage wird deutlich, mit welcher Wucht die Codierungen der Liebe zuschlagen können. Das scheinbar nur Formelhafte wird gerade auf Grund seiner Formelhaftigkeit zu einer Sprachhandlung, deren Performanz nicht etwa nur einen Pakt schließt, sondern einen Pakt erzwingt, eine Formel herauspresst, die im Grunde nicht notwendigerweise so gegeben werden muss. Aber wir haben es im Grunde mit einem Akt - zugegeben - sanfter Gewalt zu tun.

So imaginiert der Liebende in Barthes' Text auch jenen utopischen Augenblick, in dem die beiden Liebenden gleichzeitig und unabhängig voneinander das Ich-liebe-Dich aussprechen, so dass hier zwar noch das Formelhafte, nicht aber der Gewaltakt in diesem Sprechen als erzwungenes Versprechen vorhanden ist. Beide kommen sozusagen zeitgleich zum Punkt. Wir sehen: Die Figur des Ich-liebe-dich hat es wahrlich in sich, und so soll uns dieses Beispiel auch dazu inspirieren, uns nicht allein die Verstrickungen der Liebe in die Gewalt, sondern auch die unbestreitbare Komplexität gerade auch der formelhaften Elemente des Liebesdiskurses näher anzuschauen.

Als letztes Beispiel einer Figur aus den Fragments möchte ich Ihnen gerne eine Grundfigur nennen, jene des Körper-Leibes, mit dem wir es - auf der Ebene der Körperlogik, aber auch des Körperwissens - im Verlauf unserer Vorlesung noch mehrfach zu tun haben werden. Wir hatten uns ja bereits mit den Differenzen, aber auch dem wechselseitigen Durchdringen von Körper-Haben und Leib-Sein ausgehend von Helmuth Plessner beschäftigt. Aus dieser relativ kurzen Figur will ich Ihnen die Anfangs- und die Schlusspassage vorstellen:

Sein Körper war in zwei Hälften geteilt: einerseits sein eigentlicher Körper - seine Haut, seine Augen -, zart, warm; andererseits seine Stimme, kurz, verhalten, Anwandlungen von Abneigung unterworfen, seine Stimme, die nicht bot, was sein Körper bot. Anders ausgedrückt: einerseits sein weicher, warmer Körper, gerade nachgiebig genug, samtig, mit seiner Befangenheit kokettierend, und auf der anderen seine Stimme - die Stimme, immer die Stimme -, dunkel, gutausgebildet, mondän usw. [...] Kalt musterte ich sein ganzes Gesicht, seinen ganzen Körper: seine Wimpern, seinen Zehennagel, den sanften Schwung seiner Augenbrauen, seiner Lippen, den Schmelz seiner Augen, jenes Muttermal, seine Art,

57 Barthes, Roland: Fragmente, S. 142. 
beim Rauchen die Finger zu spreizen; ich war fasziniert - und doch war die Faszination insgesamt nur der äußerste Punkt der Losgelöstheit -, fasziniert von dieser Art kolorierter, porzellanener, zu Glas erstarrter Schönheit, in der ich, ohne irgend etwas davon zu verstehen, die Ursache meiner Begierde lesen konnte. ${ }^{58}$

In dieser Passage wird sehr eindrucksvoll vorgeführt, wie der Körper des anderen in ein dem Blick des anderen und dem Gebrauch durch den anderen ausgelieferten, brauchbaren Körper als Objekt, das begehrt wird, und eine Stimme zerfällt, die widersprüchlich ist, die weit mehr die Anwesenheit des anderen unterstreicht, der seine eigenen Gedanken, auch seine abweisende Haltung, kontrollieren kann. Die Stimme ist die Präsenz des anderen als Subjekt, vielleicht auch in der Form des Leibes, während der Körper wesentlich stärker unter dem Aspekt des Gebrauchtwerdens, der Objektwerdung oder Objektivierung zu verstehen ist. Dieser Körper zerfällt in seiner Objektivierung, in seiner Vergegenständlichung, auch in den zerstückelten Körper, wird an verschiedenen Punkten isoliert wahrgenommen, von den Wimpern bis zum Fußzeh. Es ist der Lacan'sche corps morcelé, jener zerstückelte Körper, der zugleich auch der erotische Körper ist, auf den sich das Begehren des Ich richtet.

Denn das Erotische geht nicht vom gesamten Körper, nicht von einer gesamten Nacktheit des Körpers, aus, sondern von einzelnen Teilen des Körpers, die sichtbar sind, die ins Auge springen, während andere Bereiche bedeckt oder verdeckt bleiben. Dass hier die kulturelle und auch religiöse Prägung eine ganz entscheidende Rolle spielen, werden wir noch sehen; aber evident ist schon jetzt, dass jede Kultur und jede Religion uns vorschreibt, welche Teile unseres Körpers sichtbar sind und welche absolut bedeckt gehalten werden müssen, während die Grenzlinien des Sichtbaren und Erahnbaren genau den prickelnden Punkt bezeichnen. In der christlich-abendländischen Kultur sind es immer das Gesicht und unsere Hände, die im Allgemeinen, wenn es die Witterung erlaubt, sichtbar gehalten werden. Dass dies nicht in allen Kulturen der Fall ist, brauche ich an dieser Stelle nicht zu erläutern. In Abhängigkeit davon findet eine Semiotisierung und auch Erotisierung der einzelnen Körperpartien statt, mit der wir uns noch beschäftigen werden.

Doch zurück zur Figur in Barthes' Fragments d'un discours amoureux. Deutlich ist die Stimme im Kontext der damaligen Diskussionen natürlich auch die Verkörperung des Textes, also der Weg oder sogar Ausweg aus dem Textualitätsdogma, das die Gruppe Tel Quel, der Barthes noch kurz zuvor zugerechnet worden war, unbeirrbar und mit zunehmendem Dogmatismus vertrat. Für die Telqueliens, etwas holzschnittartig ausgedrückt, war alles Text, waren alle

58 Barthes, Roland: Fragmente, S. $158 \mathrm{f}$. 


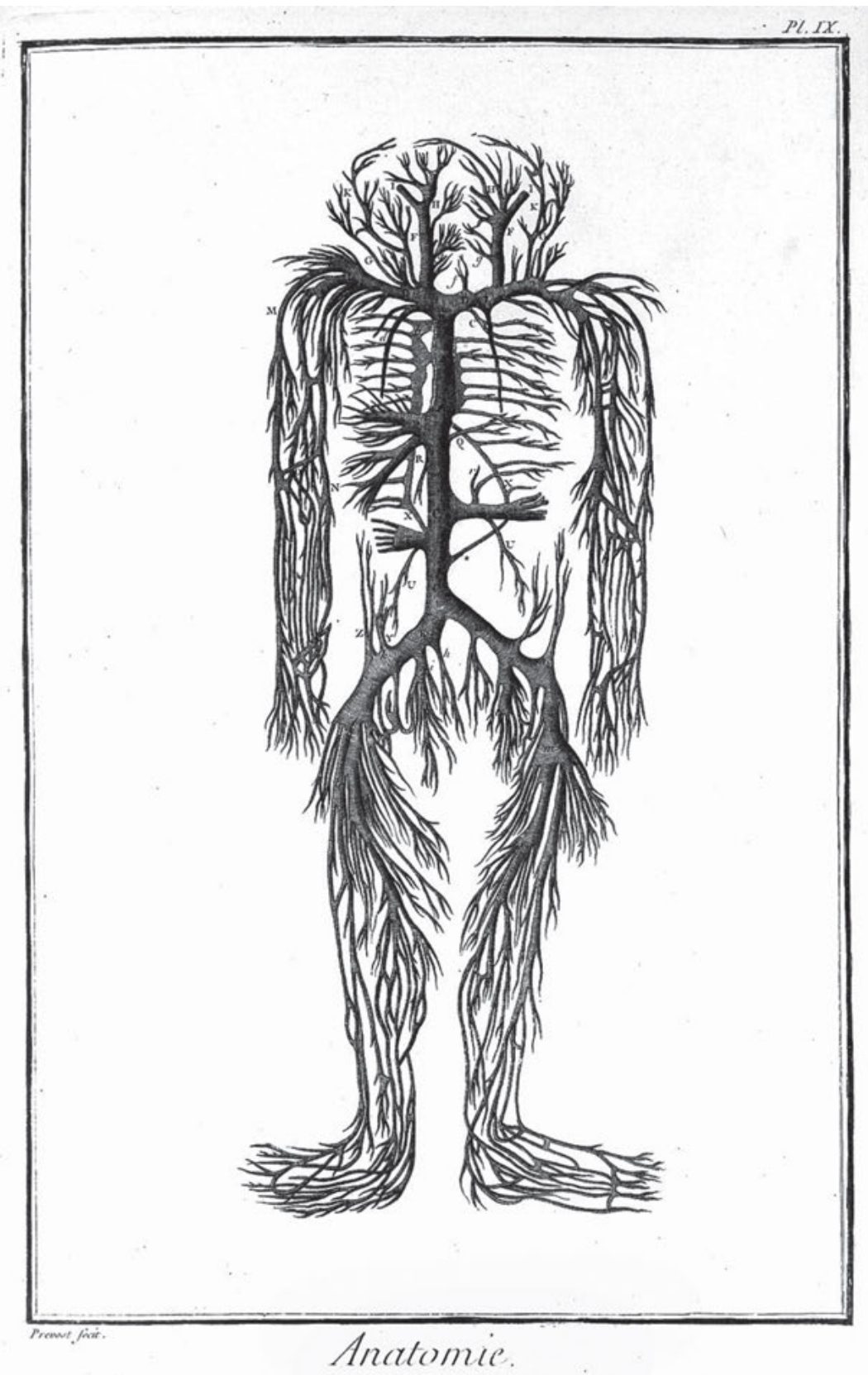

Abb. 29: „Les troncs de la veine cave avec leurs branches disséquées dans un corps adulte, \&c. d'après les Transactions Philosophiques“, Kupferstichtafel aus der Encyclopédie, nach einer Zeichnung von James Drake. 
Zeichen außersprachlicher Wirklichkeit als Texte lesbar und nur der Text vorhanden. Allein zu dieser Frage, wie also von der Textualität bei Annahme des Todes des Autors bzw. jeglicher Art von Subjektivität wieder wegzukommen wäre, könnte sich eine ganze Vorlesung widmen, die damit freilich einen zentralen Punkt der hitzigen Debatten in der zweiten Hälfte des 20. Jahrhunderts berühren würde.

Wir erkennen erneut eine terminologische Scheidung, deren Wichtigkeit gerade auch für unsere Vorlesung Sie sicherlich bemerkt haben: die Unterscheidung zwischen dem Körper als Objekt, als Körperhaben, als eine Objekthaftigkeit, als Körper, über den verfügt werden kann, und als Leibsein, als der gleichsam bewohnte, vom Subjekt geführte Körper, der Schmerz, Lust und Freude empfinden kann, der nicht als das Objekt sowohl des Anderen als auch des Ich dient. Die Objektivierung des Körpers des Anderen ist im zweiten Teil des obigen Zitats sehr deutlich, denn hier wird sein Körper gleichsam zum erstarrten, Objekt gewordenen, dem Blick preisgegebenen Körper, der eine Faszination ausübt, das Ich in seinen Bann schlägt, ohne dass es doch wüsste, warum dies so ist und was ihm da eigentlich geschieht. Der Körper des Anderen ist für das liebende Ich nicht nur ein Spielfeld der eigenen Liebesprojektionen, sondern auch ein Faszinosum, dem es sich nicht entziehen kann. Er zieht den Blick auf sich und bannt ihn zugleich. Die Stimme des Anderen aber zeigt an, dass es jenseits des Habens des anderen Körpers noch ein inkommensurables $\mathrm{Du}$ in seiner Komplexität gibt.

Im weiteren Verlauf der Vorlesung werden wir immer wieder die Figuren von Roland Barthes heranziehen, um mit Hilfe seiner Fragments d'un discours amoureux jeweils interessante Punkte im Liebesdiskurs zu beleuchten, die uns vielleicht ohne den französischen Kulturtheoretiker nicht so einfach zugänglich gewesen wären. Die Fragmente dienen uns in der Folge ebenso als Theorie des Liebesdiskurses wie auch als literarisches Vergleichsstück, das seine eigene Vieldeutigkeit besitzt.

Abschließend soll kurz von einer Vorlesung die Rede sein, die Roland Barthes am Collège de France hielt und die nach seinem Tode in Buchform publiziert wurde. Es existiert auch ein Mitschnitt auf mehreren CD's, den ich aber lieber nicht verwende, ist die Lautstärke der Studierenden doch wahrlich ohrenbetäubend und gewiss kein gutes Beispiel für Sie. Freilich kann man dabei auch die souveräne Ruhe bewundern, mit welcher der längst zum internationalen Star avancierte Barthes seine Vorlesung und seine oftmals auch recht vorläufigen Überlegungen durchzog.

In ihr gibt es einen Gedanken, der genau die Problematik der Objektwerdung, jenen Augenblick also darstellt, an dem der Andere für den Liebenden zu einem Bild wird, das er sich geformt hat, wobei genau dies das gemeinsame Zusammen- 
leben nicht länger ermöglicht. Dies ist ein fürwahr einschneidender Augenblick, dem Barthes all seine Aufmerksamkeit widmete. Das sehr wohl lebenswissenschaftliche Thema der Vorlesung lautete Comment vivre ensemble, und es ging im Grunde um eine Lektüre von Literatur als Simulation des Lebens, die ihrerseits eine Unmenge an Wissen über das Leben gespeichert hat. In diesem Kontext heißt es gegen Ende in einem auf der Auswertung unterschiedlichster philosophischer und literarischer Texte beruhenden Versuch, eine Utopie des Zusammenlebens selbstreflexiv zu entwickeln:

Man würde an dieser Stelle wieder diesen Wert erreichen, den ich Schritt für Schritt unter dem Namen der „délicatesse“ definieren werde (ein etwas provokantes Wort in der heutigen Welt). Délicatesse will sagen: Distanz und Achtung, Abwesenheit von Gewicht in der Beziehung, jedoch zugleich lebendige Wärme dieser Beziehung. Das zu Grunde liegende Prinzip wäre: den anderen, die anderen nicht herumschubsen, nicht manipulieren, aktiv auf alle Bilder verzichten (von den einen wie den anderen), alles vermeiden, was das Imaginäre der Beziehung alimentieren könnte..$^{59}$

Gleich in seiner ersten Vorlesung am renommierten Collège de France untersucht Barthes also die Grundbedingungen menschlichen Zusammenlebens vorrangig nicht anhand soziologischer Befunde oder juristischer Untersuchungen, sondern auf eine gänzlich andere, im Grunde unerhörte Art: Er zieht die Literatur als Quelle heran und greift ihre Anregungen auf. Denn die Literaturen der Welt können Wesentliches zur Diskussion unterschiedlichster Formen des Zusammenlebens in Differenz - und somit zu einer der Grundfragen einer lebenswissenschaftlich perspektivierten Philologie - beisteuern.

In einer Welt, die zweifellos im gesamten 20. Jahrhundert, insbesondere aber seit den achtziger Jahren und wohl weit über unsere Tage hinaus, fundamental von Migrationen gekennzeichnet ist, ist die Frage nach multikulturellen, interkulturellen und transkulturellen Beziehungen und Formen des Zusammenlebens von ungeheurer Wichtigkeit. Denn welches sind die Voraussetzungen und Grundbedingungen einer gelingenden Konvivenz? Wie können wir diese Rahmenbedingungen erkennen? Und wie können wir sie gesellschaftlich implementieren?

Literatur soll hier unsere vorrangige Bezugsquelle sein. Denn sie beruht auf Forschung, auf unendlich vielen, von wichtigen Persönlichkeiten zusammengetragenen Untersuchungen, die nicht in einer monologischen Art und Weise und nicht mit Hilfe einer eindeutigen, jegliche Vieldeutigkeit vermeidenden Sprache

59 Barthes, Roland: Comment vivre ensemble. Simulations romanesques de quelques espaces quotidiens. Notes de cours et de séminaires au Collège de France, 1976-1977. Paris: Seuil 2002, S. $170 f$. 
zusammengestellt wurden. Vielmehr geht es in der Literatur ums Ganze - und dies heißt auch: um das Vermeiden jeglicher Reduktionen, jeglicher Vereindeutigungen. Vielfalt des Denkens, des Lebens, auch des Liebens gegen die um sich greifende Einfalt in unserer heutigen Welt. Anders gesagt: Es geht in den Literaturen der Welt nicht um die Repräsentation von Wirklichkeit, sondern um die Darstellung einer gelebten Wirklichkeit, von gelebten Wirklichkeiten, die in ihrer ganzen Vieldeutigkeit, in ihrer Polysemie und Polylogik erfasst werden müssen und als lebbare Wirklichkeiten gesellschaftlich zu etablieren sind.

Insofern bilden die Literaturen der Welt nicht allein ein Frühwarnsystem und ein seismographisches Beobachtungsnetz, das sich über den gesamten Planeten erstreckt, sondern auch ein Laboratorium oder vielleicht besser noch einen Spiel-Raum, innerhalb dessen die unterschiedlichsten Formen des Nebeneinanderherlebens, des Zusammenlebens und der Bewegungen quer zu den Kulturen erprobt, in Frage gestellt und in unterschiedlichen Konstellationen untersucht werden können. Die Erfassung dieser Dimensionen von Literatur ist heute überlebenswichtig.

Roland Barthes hat in seinen Vorlesungen, aber auch in vielen seiner Schriften in der Tat ein Zusammenleben literarisch erprobt, das ihm im praktischen Leben nur bedingt gelang, wenn wir einmal sein lebenslanges Zusammenleben mit seiner Mutter Henriette Barthes ausklammern. Literatur hält also nicht den Schlüssel für ein glückliches Zusammenleben bereit - das wäre denn doch zu einfach. Aber die Literatur führt uns Lebensmöglichkeiten vor, erweitert radikal unseren Horizont an Alternativen, zu denen uns im Alltagsleben oft die Phantasie fehlt. Genau diese phantasierten, aber dennoch real lebbaren Möglichkeiten der Konvivenz offeriert sie uns. Wir müssen die Literaturen der Welt nur anders lesen, um uns diese Lebensalternativen konkret vor Augen halten zu können.

Eine gelingende Konvivenz schließt selbstverständlich die Konzeptionen und Verwirklichungen von Liebe mit ein. Dabei wird zugleich auch deutlich, dass Liebe letztlich auch diese Frage beinhaltet: Inwieweit es möglich ist, den anderen in seiner Differenz zu lassen, ohne ihm gegenüber auf längere Zeit zunehmend indifferent $\mathrm{zu}$ werden. Ohne ihn oder sie herumzuschubsen, $\mathrm{zu}$ manipulieren, zu unserem Objekt zu machen, unserer Gewalt - und sei es aus Liebe - zu unterwerfen. Dieser Frage stellt sich Roland Barthes. Genau dies ist aber eine Frage, welche die Filme Hollywoods, die stets mit dem Schild Just married enden, nicht $\mathrm{zu}$ beantworten vermögen. Was immer auch nach dem coup de foudre, nach der ersten Nacht, nach dem Ja-wort oder was an Szenen der Liebe insgesamt auch immer imaginiert werden kann, weiter geschehen wird ... im Film!

In ihm geht eine ganze Produktionsmaschinerie, eine industrielle Schwerindustrie in Stellung, um unsere Imaginationen und Bedürfnisse $\mathrm{zu}$ befriedigen, aber vielleicht weniger, um uns Lebensalternativen vor Augen zu führen. 
In der Literatur sind es nur einzelne Individuen, die im intertextuellen Rückgriff auf andere Texte ihre Forschungen und Untersuchungen in Worte fassen; und sie bedürfen lediglich einer Leichtindustrie, eines Verlagssystems, um mit einer Leserschaft $\mathrm{zu}$ kommunizieren und in Verbindung $\mathrm{zu}$ treten. Gewiss sprechen auch hier beherrschende Marktkonzerne ein gewichtiges Wort mit. Aber selbst wenn ich hier nur holzschnittartig argumentieren kann, so ist doch deutlich, dass die Forschungen der Literaturen der Welt schon strukturell wesentlich weiter und radikaler gehen können als etwa die von großen Produktionsfirmen überwachte Filmindustrie, die Produktion all jener Bilder, die unser Imaginäres filmisch bilden.

Lassen Sie mich diesem Teil abschließend noch hinzufügen, dass das große Gefühl der Liebe seit allen Anfängen der Literaturen der Welt an da ist: ebenso im Shi Jing wie im Gilgamesch-Epos. Im letztgenannten Epos werden im Übrigen fast alle denkbaren Formen der körperlichen und unkörperlichen Liebe durchstudiert: von der Liebe zu den Göttern und zu den Tieren, über die heterosexuelle und die homosexuelle Liebe, die brüderliche Liebe wie die mütterliche Liebe, bis hin zur Liebe der Götter sowie die Liebe zwischen den Göttern und den Menschen, und so weiter. Dass in diesem Epos aus dem Zweistromland Mesopotamien - wie später auch in Griechenland - nicht alles auf die heterosexuelle Liebe eingeschränkt ist, versteht sich von selbst und verweist zugleich auf die radikale Eingrenzung und Beschränkung der Liebeskonzeptionen, wie sie sich historisch im Abendland herausgebildet haben. Dennoch will ich mich in dieser Vorlesung grosso modo auf jenen discours amoureux beschränken, wie ihn Roland Barthes für uns abgesteckt hat. Seine Fragments d'un discours amoureux eröffnen durch die geschlechtliche Nicht-Identifizierung des LiebendenDiskurses einen Horizont von sehr diversen Liebesdiskursen und Liebespraktiken, die heute - wenn auch bei Weitem nicht weltweit - in den Kanon der Formen und Normen von Liebe übergegangen sind. Mit diesen Lebensformen und Erlebensformen der Liebe und ihrer Aneignung durch die Formen und Normen unseres geschichtlich gewordenen Lesens möchte ich mich befassen und dazu einen weiteren Schritt tun. 